\title{
The effects of competition and herbicide drift on non- target plant populations
}

\author{
by \\ Kaitlyn Montroy, H. B.Sc.
}

A thesis submitted to the Faculty of Graduate and Postdoctoral Affairs in partial fulfillment of the requirements for the degree of

Master of Science

in

Biology

Specialization in Chemical and Environmental Toxicology

Carleton University

Ottawa, Ontario

C) 2016, Kaitlyn Montroy 


\section{Abstract}

Herbicide drift is the movement of herbicide away from its intended target. The effect of drift on non-target plants is considered in environmental risk assessments, where the goal of the assessment is to protect plant populations and communities. The aim of this study was to evaluate the assumption that the single species tests used in risk assessments are fully protecting wild plant populations, as they do not account for interspecific interactions. In a greenhouse two-species competition experiment, it was found that the competitive interactions between the model species, Centaurea cyanus and Silene noctiflora, were affected by low doses of glyphosate representing drift. These changes could affect both of their populations in the long-term, and would not be detected using current test guidelines. As interspecific competition is an important determinant of plant community structure, competitive interactions may need to be included in risk assessment to make more credible predictions on the effects of herbicide drift on non-target plants. 


\section{Acknowledgements}

My greatest achievement to date is accomplished with the submission of this thesis. Yet, it would not have been possible without many others. First and foremost, I need to extend my gratitude to my supervisor, Dr. Céline Boutin, for her continued support and enthusiasm throughout these past two years. I have been extremely fortunate to be of her grad students, benefitting from her knowledge and constructive criticism. Also thanks to Dr. Steven Cooke for his helpful comments as co-supervisor.

Thanks to David Carpenter for great advice and support during the experiment and writing of this thesis, and to Simon Grafe and Carly Casey for help in measuring plant heights and counting tons of flowers over several months! Thanks to them and other lab mates Anna Lukina, Jane Allison and Danielle Dowd for providing encouragement and lots of laughs to help relieve the stress.

This project was the result of international collaboration between Environment and Climate Change Canada and Aarhus University in Denmark. Thank you to the researchers in Denmark - Solvejg Kopp Mathiassen, Dr. Beate Strandberg, Dr. Christian Damgaard and the other members of the PENTA (Pesticide effects on non-taget terrestrial plants at individual, population and ecosystem levels) project team- for collaborating and designing the PENTA project with Céline and David. Extra special thanks to Christian for statistics, and for being patient with me over numerous emails and skype sessions as I tried to understand his competition model used for this research. I also need to thank Drs. Andrew Simons and John Arnason for their insight as my committee members. Also thanks to Ed Bruggink for help with the greenhouse space, especially pests. 
I also need to thank my very supportive fiancé, Marc Lalonde, for his encouragement. It would not have been possible to remain so uplifted when times were rough if it were not for him. 


\section{Table of Contents}

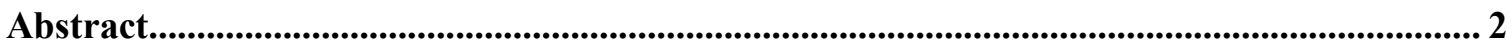

Acknowledgements …….............................................................................................. 3

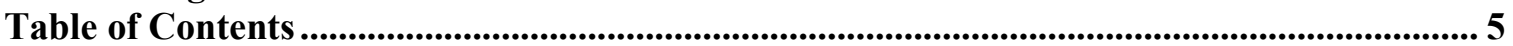

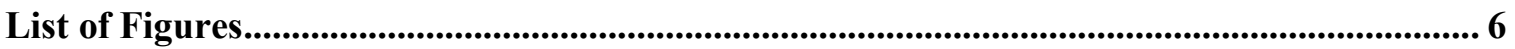

List of Tables ................................................................................................................................... 8

List of Appendices................................................................................................................................ 9

List of Abbreviations ........................................................................................................................ 10

Chapter 1: Introduction ........................................................................................................................... 11

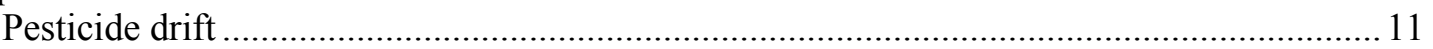

Importance of field margins ...................................................................................... 12

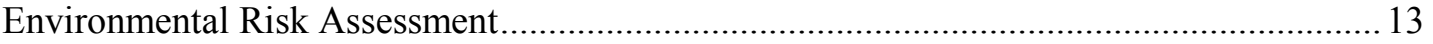

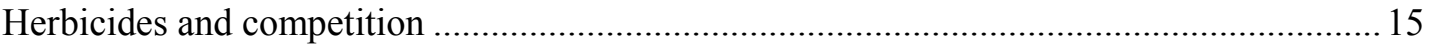

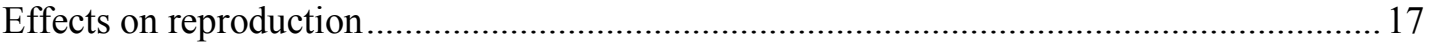

Trophic consequences of changes in plant communities .................................................... 19

Including competition in Environmental Risk Assessment ................................................22

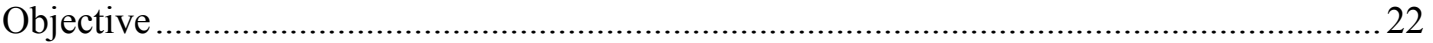

Chapter 2: Materials and Methods .............................................................................................22

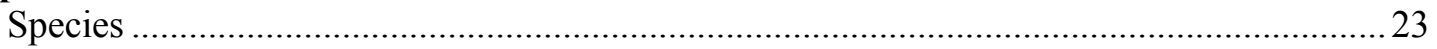

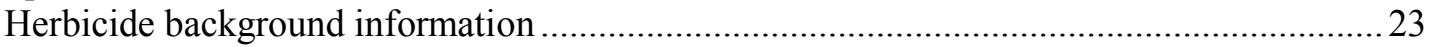

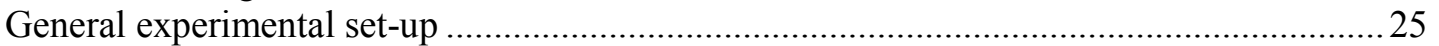

Vegetative assessments ..............................................................................................2

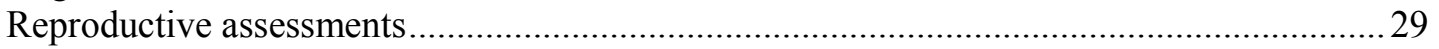

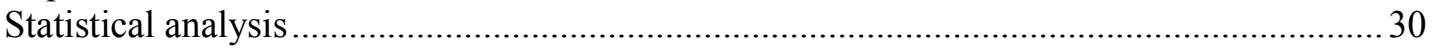

Chapter 3: Results............................................................................................................................ 33

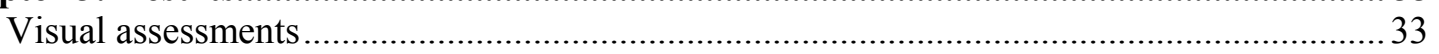

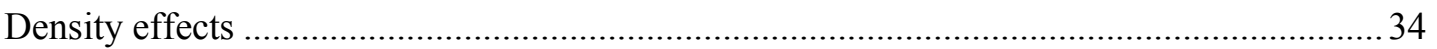

Height, diameter, duration and time to first flowering, seed weight, and germination...........34

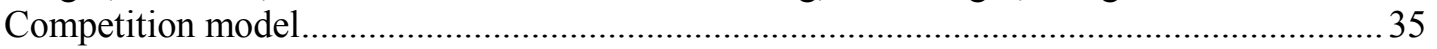

Relationships between endpoints ....................................................................................

Chapter 4: Discussion ..........................................................................................................57

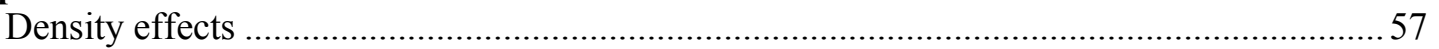

Glyphosate and competition effects on height, time to flower and seed weight.....................58

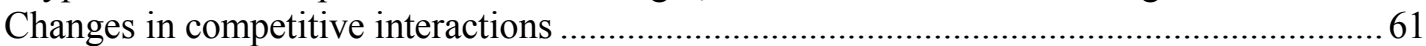

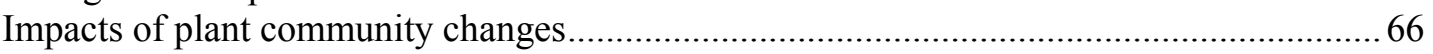

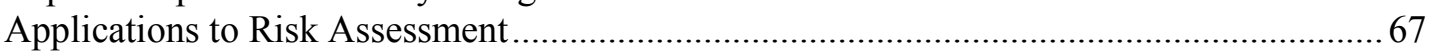

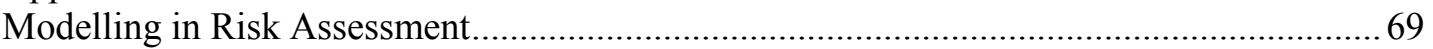

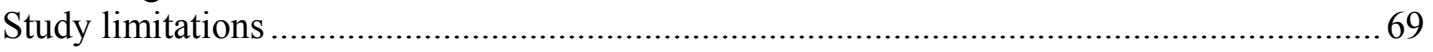

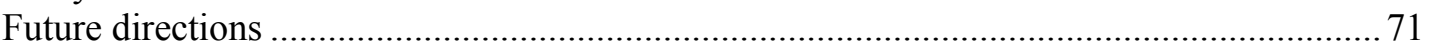

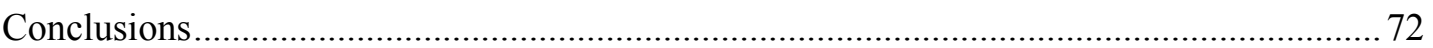

References............................................................................................................... 73

Appendix 1 ........................................................................................................................................... 8 


\section{List of Figures}

Figure 1. Compositions of the densities and proportions in pots used to study herbicide drift and competition between $C$. cyanus and S. noctiflora. 27

Figure 2. Average maximum height with standard error of $C$. cyanus in competition with conspecifics and $S$. noctiflora in various mixtures, sprayed with different doses of the herbicide glyphosate. 38

Figure 3. Average maximum diameter with standard error of $C$. cyanus in competition with conspecifics and $S$. noctiflora in various mixtures, sprayed with different doses of the herbicide glyphosate. 39

Figure 4. Average number of days until flowering with standard error of C. cyanus in competition with conspecifics and $S$. noctiflora in various mixtures, sprayed with different doses of the herbicide glyphosate.

Figure 5. Average duration of flowering with standard error of $C$. cyanus in competition with conspecifics and $S$. noctiflora in various mixtures, sprayed with different doses of the herbicide glyphosate.

Figure 6. Average seed weight with standard error of C. cyanus in competition with conspecifics and $S$. noctiflora in various mixtures, sprayed with different doses of the herbicide glyphosate. 42

Figure 7. Average proportion of seeds germinated with standard error of C. cyanus in competition with conspecifics and $S$. noctiflora in various mixtures, sprayed with different doses of the herbicide glyphosate.

Figure 8. Average speed of germination with standard error of $\mathrm{C}$. cyanus in competition with conspecifics and S. noctiflora in various mixtures, sprayed with different doses of the herbicide glyphosate.

Figure 9. Average biomass and standard error of $S$. noctiflora when in competition with conspecifics and $C$. cyanus in various mixtures at different doses of the herbicide glyphosate.

Figure 10. Average number of flowers and standard error produced by C. cyanus when in competition with conspecifics and $S$. noctiflora in various mixtures at different doses of the herbicide glyphosate. 46

Figure 11. Average number of seeds and standard error produced by $C$. cyanus when in competition with conspecifics and $S$. noctiflora in various mixtures at different doses of the herbicide glyphosate.

Figure 12. Height of $C$. cyanus in monocultures and mixtures with $S$. noctiflora at different doses of glyphosate.

Figure 13. Days until flowering of $C$. cyanus in monocultures and mixtures with $S$. noctiflora at different doses of glyphosate. 48

Figure 14. Seed weight of $C$. cyanus seeds in monocultures and mixtures with $S$. noctiflora at different doses of glyphosate. 49 
Figure 15. Relationship between the number of days until flowering and the duration of flowering of $C$. cyanus at different densities and doses of the herbicide glyphosate. Diamond shapes represent low density pots (1-9 plants), circles medium density (16-40 plants), and triangles high density (48-64 plants).

Figure 16. Relationship between the number of days until flowering and the total number of flowers produced by $C$. cyanus at different densities and doses of the herbicide glyphosate. Diamond shapes represent low density pots (1-9 plants), circles medium density (16-40 plants), and triangles high density (48-64 plants). 54

Figure 17. Relationship between $C$. cyanus flower and seed production at different densities and doses of the herbicide glyphosate. Diamond shapes represent low density pots (1-9 plants), circles medium density (16-40 plants), and triangles high density (48-64 plants).

Figure 18. Relationship between $C$. cyanus seed weight and the proportion of germinated seeds at different densities and doses of the herbicide glyphosate. Diamond shapes represent low density pots (1-9 plants), circles medium density (16-40 plants), and triangles high density (48-64 plants)..... 55

Figure 19. Relationship between $C$. cyanus seed weight and the speed of germination at different densities and doses of the herbicide glyphosate. Diamond shapes represent low density pots (1-9 plants), circles medium density (16-40 plants), and triangles high density (48-64 plants). 


\section{List of Tables}

Table 1. Experimental Design .................................................................................... 28

Table 2. Results of statistical analysis for the effect of glyphosate dose on various endpoints. Significant endpoints are bolded. 50

Table 3. Results of statistical analysis comparing the relative differences between plants in competition and the individual plants at the same dose. Significant endpoints are bolded.

Table 4. Calculated percentiles of the marginal posterior distribution of parameters of $S$. noctiflora biomass and C. cyanus flower production. Bolded numbers indicate parameter significance.

Table 5. Calculated percentiles of the marginal posterior distribution of parameters of $S$. noctiflora biomass and C. cyanus seed production. Bolded numbers indicate parameter significance.

Table 6. Studies examining the effects of herbicide on competition or plant mixtures... 65 


\section{List of Appendices}

Appendix 1. Visual rating system for plants used to assess herbicidal damage each week after exposure to 1 and $5 \%$ of the recommended label rate of glyphosate. 


\section{List of Abbreviations}

a.e.: acid equivalent

AMPA: Aminomethylphosphonic acid

EFSA: European Food and Safety Authority

EPSP: 5-enolpyruvylshikimate-3-phosphate

ERA: environmental risk assessment

MEA: millennium Ecosystem Assessment

NTTP: non-target terrestrial plants

OECD: Organization of Economic Co-operation and Development

PAR: photosynthetically active radiation

USEPA: United States Environmental Protection Agency 


\section{Chapter 1: Introduction}

Human domination of the natural world has led to unprecedented changes in biodiversity and environmental quality (Vitousek et al. 1997). For example, agricultural intensification over the past few decades has been a substantial contributor to environmental issues. Nearly a quarter of Earth's land surface has been converted into agricultural landscape (Millenium Ecosystem Assessment (MEA) 2005), and this modification can cause major degradation and loss of natural habitats (Lichtenberg 2000). This has resulted in the need to protect the natural habitats that remain in managed agroecosystems (Boutin \& Jobin 1998). However, modern agriculture is highly dependent on external inputs such as pesticides (Kleijn \& Snoeijing 1997), and this can compromise the health of these remaining natural habitats and the organisms within them.

\section{Pesticide drift}

When pesticides are sprayed on agricultural fields, some of the particles move away from the targeted crop area. This process, known as drift, unintentionally exposes non-target organisms to pesticides (United States Environmental Protection Agency (USEPA) 2015). Such exposure can be due to drift that occurs as a result of air movements during application (spray drift) or due to the evaporation of the pesticide from surfaces after application (vapour drift) (European Food and Safety Authority (EFSA) 2014). Drift always occurs to some extent, and is affected by factors such as the equipment (e.g. Davis \& Williams 1990; Murphy et al. 2000; Johnson et al. 2006), the pesticide (e.g. Grover et al. 1972; Hilz \& Vermeer 2013), and the weather conditions around the time of spray (e.g. Elliott \& Wilson 1983; Craig et al. 1998). Generally, 
between 1 and $10 \%$ of the application rate will drift within 10 metres of the spraying equipment when ground equipment is used (Boutin \& Jobin 1998), but distances of up to 500 meters with aerial applications have been noted (e.g. Maccollom et al. 1986; Davis \& Williams 1990). Although the drift doses may seem low, there are many studies documenting the direct and indirect effects that pesticide drift has on a variety of nontarget organisms (e.g. Potts 1980; Bhatti et al. 1995; Egan et al. 2014). Most drift deposits in the field margins (Kleijn \& Snoeijing 1997), which are the most common type of natural habitat remaining in agroecosystems (Boutin \& Jobin 1998). Therefore, the toxicological effects are greatest in the margins (Kleijn \& Snoeijing 1997) - the same natural areas we are aiming to maintain in disturbed agricultural landscapes.

\section{Importance of field margins}

Herbicides are the most widely used pesticide worldwide (USEPA 2011), and their vast use raises concerns about the effects of herbicide drift on non-target organisms, particularly non-target terrestrial plants (NTTPs) in the field margins. Field margins can harbor hundreds of plant species (EFSA 2014), and it is in these regions that plant biodiversity in agricultural landscapes is maintained (e.g. Marshall \& Moonen 2002; Deckers et al. 2004). As plants form the basis of ecosystems, any effects on wild plants caused by herbicide drift can affect wildlife both directly and indirectly. These plants support the food web in the agroecosystem and are sources of habitat and shelter for other organisms (Kleijn \& Snoeijing 1997), and can also act as corridors of dispersal (e.g. Burel 1989; Corbit et al. 1999). Therefore the loss of plants in field margins can cause overall declines in farmland biodiversity (Boutin et al. 2011). 
The importance of wild plants remaining in field margins can also be stressed in terms of their importance to ecosystem services, which are the benefits that humans receive from ecosystems (MEA 2005). Many ecosystem services in agricultural areas are driven by NTTPs (EFSA 2014), and these services are crucial for all lives on earth, including humans (MEA 2005). These services include pest control though sheltering beneficial invertebrates and birds, helping to prevent soil erosion, driving nutrient cycling, protecting water bodies from agrochemical drift, and increasing pollination of crops by attracting pollinators to the field, among others (Altieri 1999; Olson \& Wäckers 2007; Norris 2008; Nicholls \& Altieri 2013). The link between ecosystem services, plants and biodiversity has been established (Hooper et al. 2005), and therefore any negative effects on biodiversity can have implications on our ability to obtain ecosystem services. Herbicide use has been identified as a contributing factor in declining plant species richness, abundance, and diversity in agroecosystems (e.g. Marrs et al. 1989; Aude et al. 2003; Gove et al. 2007; Boutin et al. 2014), and changes in species compositions in field margins have been noted (Jobin et al. 1997; de Snoo 1999). Therefore, to protect biodiversity and ecosystem services, it would be useful to be able to predict the impacts of herbicide drift on plants in field margins (Damgaard et al. 2014).

\section{Environmental Risk Assessment}

Due to the potential impacts of herbicides on NTTPs in agroecosystems, the effects of drift are becoming more important aspects of environmental risk assessment (ERA) for pesticide registration (Weisser et al. 2002). ERAs are conducted prior to herbicide marketing, and must demonstrate that the herbicide has no unacceptable effects on the environment, including NTTPs. The general goal of the ERA for terrestrial plants 
is to maintain species biodiversity in agroecosystems -aiming to protect the abundance and diversity of non-target plant species, meaning that herbicides should have no longterm effects (EFSA 2014).

ERA generally follows a three-tiered approach. Tier $\mathrm{I}$ is a preliminary assessment, where species are exposed to the highest application rate. If more than a 50\% effect is determined, tier II must be performed, which are the dose response tests. For herbicides, most often the tier II must be performed. Both Tiers I and II are greenhouse experiments using individually potted plants or monocultures. These tests are quick, simple and relatively inexpensive, and they are reproducible (Boutin et al. 1995). Tier III is, however, more realistic, and studies the effects of pesticides under various biotic and abiotic conditions using microcosms or field studies, or using natural communities (EFSA 2014). However, no protocol currently exists for this kind of risk assessment. When the risk from tier II studies can be mitigated, there is no need for higher tier testing (EFSA 2014). However, due to the importance of plants as the foundations of our ecosystems, it has been put forth by EFSA (2014) that they should be considered in higher tiered testing. Further, responses of plants in greenhouses are not always equivalent to those in the field (e.g. Riemens et al. 2008; Dalton \& Boutin 2010). Individual level or monoculture tests in the greenhouse lack the variable abiotic conditions of the outdoors, as well as the biotic interactions that occur between members of a community, such as competition (EFSA 2014). This leaves gaps in lower tiered testing.

The current ERA test guidelines for NTTPs at tier I and tier II have been developed by the Organization for Economic Cooperation and Development (OECD 
2006) and the USEPA (USEPA 2012). The phytotoxicity tests are conducted using 6-10 species (normally crops used as proxy), grown individually or in monocultures in the greenhouse. The plants are sprayed as seedlings or at the 2-6 leaf stage, and assessed about three weeks after spray at the vegetative stage. However, these guidelines are currently being questioned in terms of their ability to be fully protective, with many shortcomings having been demonstrated. For instance, studies aiming to assess whether using crops as surrogates for wild species is acceptable have been inconclusive, with some finding crops to be less sensitive than NTTPs (e.g. Boutin et al. 2004; Schmitz et al. 2012), while others finding no differences (e.g. Carpenter \& Boutin 2010; White \& Boutin 2007). Another is that wild plants are exposed to herbicides at various phenological stages, and sensitivity varies depending on timing of exposure (Boutin et al. 2000; Strandberg et al. 2012; Boutin et al. 2014). Further, reproductive endpoints are not required (Strandberg et al. 2012; EFSA 2014), and the effects of natural plant interactions combined with the herbicide are not considered (Marrs et al. 1991a; Damgaard et al. 2008).

\section{Herbicides and competition}

As the overall protection goal is to preserve biodiversity at the population and ecosystem level (EFSA 2014), an important question is whether responses of plant populations are equivalent to the responses of individual plants or single species, as assumed in ERA test guidelines. Direct consequences of herbicide exposure often include discoloration, chlorosis, necrosis and poor growth, but plants may also be affected more indirectly through changes in competitive balances with its neighbours (Marrs et al. 1993). Plant-plant interactions may be important in two ways in terms of herbicide drift: 
herbicide deposition on individual plants can be affected by the structure of its neighbours, and any adverse effect on the performance of one species can promote the growth of others (Marrs et al. 1991a). Therefore, the effect of an herbicide may depend strongly on a plant's competitors. For instance, an experiment by Damgaard et al. (2008) predicted that Geranium dissectum L. would outcompete Capsella bursa-pastoris (L.) Medik. in a competition experiment when exposed to the herbicide mecoprop-P. This was predicted based on the results of individual level tests, in which $G$. dissectum was less sensitive. However this expectation was not met in experiments as the interspecific competitive abilities of both species increased significantly when exposed to the herbicide. As phytotoxicity tests in ERA are performed using individually potted plants, these competitive interactions are not considered and could make individual level and single species test results less credible.

Neighbouring plants are an important limiting biotic factor for plant growth and reproduction (Damgaard 2004). Individual plants in a natural community will compete not only with conspecifics (intraspecific competition) but also with members of other plant species (interspecific competition) for limited resources (Harper 1977). As a result of these limited resources, negative interactions between neighbouring plants are common (Damgaard 2004). The competition that arises is thought to be one of the most important factors influencing the composition of plant communities (e.g. Rees et al. 1996; Weiher et al. 1998).

As plant species have different sensitivities to herbicides, it can be expected that herbicide drift will affect competition by inhibiting some plant species more than others (Damgaard et al. 2014). If herbicide drift is affecting the competitive relationships 
between species, the result can be a community change in the long-term, as more sensitive species will be outcompeted and displaced by more tolerant ones (Boutin \& Jobin 1998; Petersen et al. 2006; Gove et al. 2007). For instance, a field study by Damgaard et al. (2014) found that low doses of glyphosate altered the competitive interactions between two grass species, Agrostis capillaris L. and Festuca ovina L.: with increasing levels of glyphosate, $F$. ovina became a better competitor than A. capillaris. This explained why F. ovina was found to be dominant in field plots treated with higher levels of glyphosate.

\section{Effects on reproduction}

Changes at the population and community levels can also be caused by adverse effects on reproductive abilities, such as changes in flowering or seed production, including seed viability. Several studies have shown reductions in flowering caused by sub-lethal doses of herbicides (e.g. Marrs et al. 1991a; Gove et al. 2007; Boutin et al. 2014; Schmitz et al. 2014; Bohnenblust et al. 2016). Delays in flowering have also been noted in several wild species (Carpenter et al. 2013; Boutin et al. 2014; Bohnenblust et al. 2016) and crop varieties exposed to a wide range of herbicides (Wall et al. 1995; Pline et al. 2003a; Pline et al. 2003b; Bohnenblust et al. 2016). Both delays and reductions in flowering can have subsequent effects on the population by affecting the number of seeds produced that year. Reductions in the amount of seeds produced by several species have been documented for many herbicides (Fawcett \& Slife 1978; Isaacs et al. 1989; Marrs et al. 1989; Fletcher et al. 1996; Taylor \& Oliver 1997; Riemens et al. 2008; Rokich et al. 2009; Carpenter \& Boutin 2010; Carpenter et al. 2013). Fewer seeds produced in a year also affect the seedbank - the natural store of seeds in the soil (Harper 1977). Declines in 
seed bank diversity have been reported in crop fields experiencing herbicide exposures (Ball 1992; Rokich et al. 2009), whereas the number of seeds in the seedbank has been found to increase when changing from conventional to organic farming (Albrecht 2005). If seedbank contributions continue to decrease, the more sensitive species will greatly decline or even be replaced by more tolerant ones (Marrs et al. 1991a; Crone et al. 2009). These effects may be especially detrimental to annual species as they need to reproduce each year (EFSA 2014).

Herbicides can also be detrimental to seed viability. Several studies have found that the herbicide glyphosate affects $F_{1}$ seed germination. A literature review by Blackburn \& Boutin (2003) determined that glyphosate inhibited germination, and this was dependent on the timing of plant exposure and the amount used. They followed up by performing a new experiment, in which seven of the 11 species tested had their seed viability decreased by glyphosate.

Detrimental effects on flowering and seeds caused by herbicides can affect the plant population's survival in the long-term by decreasing recruitment for the next generation (EFSA 2014). Further, these reductions can have long-term effects on plant communities as more tolerant species will not have their reproduction affected as adversely, and species composition can shift as the more sensitive species are replaced. Even though adverse effects on reproduction can harm the population and community dynamics, reproductive endpoints are currently not required in ERA. The most common endpoints used are biomass and assessments of visible effects such as stunted growth and chlorosis (EFSA 2014), even though several studies have shown that reproductive endpoints are more sensitive than the vegetative ones (Fletcher et al. 1993; Riemens et al. 
2009; Carpenter \& Boutin 2010; Strandberg et al. 2012; Boutin et al. 2014). One of the reasons this may be is that while some plants have been noted to be able to recover from initial losses of biomass (Marrs et al. 1991b; Riemens et al. 2009; Carpenter et al. 2013), the energy required to do so may alter reproductive success (EFSA 2014). Recovery could be further hindered by competition, where again more sensitive species get outcompeted. As such, solely assessing the effects on vegetative structures may be underestimating the sensitivity of NTTPs (EFSA 2014).

\section{Trophic consequences of changes in plant communities}

Since plants form the energetic basis of ecosystems, changes in diversity and community composition can likely affect other organisms in agricultural ecosystems (Schmitz et al. 2012). Herbicides causing reductions in flowering plant species (Lagerlöf et al. 1992; Longley \& Sotherton 1997; Holzschuh et al. 2007), can have cascading effects through trophic levels and impact ecosystem services - most notable would be effects on pollinators. Pollinators cannot be sustained by short-term flowering crop species, and require food from the wild species surrounding agricultural fields (Holzschuh et al. 2007). Indeed, increased floral diversity in agroecosystems has been linked to more pollinators due to greater resource availability (reviewed in Nicholls et al. 2013) and increases pollination of crops (Holzschuh et al. 2012), which is an essential ecosystem service. Herbicides can affect pollinators through the delays and reductions in flowering that they may cause. Many pollinators are sensitive to flowering time, and the delays can cause mismatches with peak pollinator activities (Santandreu \& Lloret 1999). This has repercussions for both the pollinators and the plants: pollinators through 
fewer resources when they are needed, and plants through loss of pollination which can affect reproduction.

Herbicides causing diversity and community changes can also affect other organisms besides pollinators. Not only are many other arthropod communities indirectly affected by herbicides through changes in their host plants, but these arthropods are often food sources for birds and mammals (EFSA 2014). Therefore changes beginning with plant communities can then have cascading effects up the food chain. One of the best documented cases of these effects is that of the Grey Partridge (Perdix perdix) in Britain. The herbicides caused decreased insect abundance due to a lack of host plants, causing a shortage of food for chicks. The result was higher chick morality, causing population declines between 1952 and the mid-1980s (Potts 1980). Indeed, chick food insects, and other beneficial insects and arachnids, have been found to be more common in unsprayed plots (Taylor et al. 2006).

\section{Including competition in Environmental Risk Assessment}

Knowing the impact that plant community changes can have highlights the importance of being able to predict these changes due to herbicides and other agrochemicals. However, with current ERA guidelines, we may not be making accurate predictions of the effects of herbicide drift on non-target plants: by using individual plants or single species tests, we know little about the long-term effects of drift on plant populations and communities (EFSA 2014). Due to the importance of interspecific competition in structuring communities, the competitive forces between species should be considered to be able to understand and predict plant community formation. One way to do so is by using two-species competition experiments. Competition experiments 
measure the size, fecundity, and aspects of the $\mathrm{F}_{1}$ generation or other ecological measures at variable densities and proportions of at least two plant species (Damgaard 2004). The type of competition (interspecific vs. intraspecific), along with density and species proportions, are key factors in competition (Harper 1977), explaining the need to use at least two species and manipulate their densities and proportions. For instance, plants may only be a strong competitor above a certain density threshold, or when another species is present at lower density (Damgaard 1998).

It is thought that the interactions between species will be affected by herbicides, but it is difficult to predict in which direction (positive or negative) the change would be for each species. Density-dependent phytotoxic effects are the differences in inhibition observed when plants are grown in different densities of soil containing toxins (Weidenhamer et al. 1989). As density increases, less herbicide is available for uptake by each plant, and the effect decreases (Weidenhamer et al. 1989). However, this would only apply to herbicides that can be taken up through the roots or if exposure is through herbicides in soil via runoff. Higher densities could also result in different effects on the two species, through an increasing "shielding" effect, whereby smaller plants are protected from herbicide deposition by larger plants (Riemens et al. 2008). On the contrary, higher densities could worsen the effect of the herbicide. Herbicide exposure constitutes a stress, and with more neighbours, the greater the impact of abiotic stressors, as theorized by Keddy (2001). Both species could be negatively affected, or due to differences in sensitivities, the levels of stress imposed by the herbicide could be different for each species. The more stressed plants could then be more easily outcompeted by more tolerant plants, and this can explain an interaction between competition and 
herbicide (Damgaard et al. 2008). As competitive interactions would be occurring in nature, considering them in ERA would increase the realism and applicability of standardized toxicity tests.

\section{Objective}

The main objective of this study was to improve ERA by evaluating the effect of an herbicide on the competitive interactions between two plant species in greenhouse phytotoxicity tests. Specifically, I tested the hypothesis that the herbicide glyphosate would influence the competitive interactions between model species Centaurea cyanus L. (Asteraceae) and Silene noctiflora L. (Caryophyllaceae) by altering one or both of their competitive effects. I predicted that density effects would exist (with plants in higher densities performing worse), but there is no way to predict how the herbicide will affect a plant's ability to compete with its neighbours, as its response to herbicide may also depend on the response of the other species. I sprayed two plant species that were planted individually, in varying densities of monoculture and in different mixtures with each other with the herbicide glyphosate. By using a Bayesian modelling approach, I determined if the intra- or interspecific competitive abilities of the two plant species are affected by small doses of the herbicide. Effectively, I intended to determine if the current practice in ERA of spraying plants individually or in monoculture is suitable and can sufficiently protect our wild plant populations.

\section{Chapter 2: Materials and Methods}

This work was conducted in collaboration with researchers at Aarhus University, Denmark. It is part of a larger study entitled "Pesticide effects on non-target terrestrial 
plants at individual, population and ecosystem levels", which has the goal of improving ERA and conservation measures for NTTPs. The experimental design was a collaborative effort, and the same experiment was conducted at both Aarhus University and Environment Canada and Climate Change. This thesis is the results of the work at Environment Canada and Climate Change.

\section{Species}

Two annual plant species, Centaurea cyanus (Common cornflower) and Silene noctiflora (Night-flowering catchfly) were chosen as the NTTPs. Both species live in arable fields, and are commonly found growing together along agricultural field margins in Europe and to a lesser extent in North America. Both serve as important sources of food for pollinating insects. The bright blue flowers of $C$. cyanus emerge between May and August, and rely on insect pollination as they are self-incompatible (Svensson \& Wigren 1984). S. noctiflora flowers between June and September; its white flowers are nocturnal, opening at night to release a fragrance to attract nocturnal moths. However, the species is self-compatible (McNeill 1980). Both are considered weed species in agricultural areas, and are both in decline in their native habitats (Sutcliffe \& Kay 2000).

\section{Herbicide background information}

Glyphosate (N-(phosphonomethyl)glycine) is the world's most commonly used herbicide in modern agriculture (Woodburn 2000). It has been marketed as the herbicide Roundup since 1974 by Monsanto (Monsanto 2014). As Monsanto's patent is now expired, many companies make their own glyphosate-based herbicides (Woodburn 2000). It is a post-emergent, systemic and non-selective herbicide used for the control of annual 
and perennial grasses and broad-leaved weeds (Franz et al. 1997). With the introduction of glyphosate tolerant crops in 1996, its use increased, with glyphosate replacing many other herbicides (Young 2006). These glyphosate-resistant crops include soybean, maize, canola, alfalfa, sugar beets and cotton, with wheat under development (Monsanto 2015). It is estimated that glyphosate use rose to 826 million kilograms worldwide in 2014 (Benbrook 2016).

Glyphosate's mode of action is the inhibition of the activity of 5enolpyruvylshikimate-3-phosphate (EPSP) synthase, an enzyme located primarily in the chloroplasts. EPSP synthase is involved in the shikimic acid pathway (Liu et al. 1997), which is used for biosynthesis of several aromatic plant metabolites, including the amino acids tyrosine, tryptophan and phenylalanine (Franz et al. 1997; Tomlin 2000). The result is the disruption of protein synthesis and growth, leading to plant death (Monsanto 2014). Only plants and some microbes use this enzyme - animals and humans do not (Franz et al. 1997).

Glyphosate is taken up through the leaves, after which it is translocated primarily through the phloem throughout the entire plant, concentrating in the actively growing tissues such as meristems (Franz et al. 1997; Tomlin 2000). Glyphosate is metabolized very little by most plants (Franz et al. 1997), with the major metabolite being aminomethylphosphonic acid AMPA (Duke et al. 2003; Reddy et al. 2004). Glyphosate kills the entire plant, including the root system, which prevents the plant from growing back (Monsanto 2014).

Glyphosate is widely used because it is cheap and effective, and has good environmental properties such as low volatility, soil binding (low mobility), and low 
bioaccumulation (Baylis 2000; Monsanto 2014). It is also naturally degraded by microbial activity into AMPA (Franz et al. 1997) and may be further degraded to natural products, mainly carbon dioxide (Giesy et al. 2000).

\section{General experimental set-up}

Experiments were conducted in the greenhouses at Carleton University, in Ottawa, ON, between January and August 2015. Average temperature ranged from 17.3 \pm 3.5 to $38.0 \pm 7.3^{\circ} \mathrm{C}$, average photosynthetically active radiation (PAR) (with no artificial lighting) ranged from 49 (cloudy day) to $1505 \mu \mathrm{mol} / \mathrm{ms}^{2}$ (sunny day) and average humidity ranged from $35.1 \pm 16.4$ to $74.1 \pm 14.1 \%$. Biological control agents (Predatory mites Neoseiulus cucumeris, Ladybugs Hippodamia convergens, and mealybug destroyers Cryptolaemus montrouzieri) were used when necessary to control for greenhouse pests (fungus gnats, thrips, aphids, and mealybugs), although there were never any large infestations. Fertilizer was added to pots when nutrient stress was detected (through discolorations) to ensure they were not limiting (Plant-Prod, 20-20-20 mix of nitrogen, phosphoric acid and soluble potash at a concentration of $2.5 \mathrm{~mL} / \mathrm{L}$, Plant Products Co. Ltd., Brampton, ON, Canada). All pots were treated equally with respect to biological control and nutrient addition.

The experimental set up consisted of 26 plant combinations $\mathrm{x} 3$ doses (including controls) x 3 replicates. In total, 234 experimental pots were used, containing 7, 416 plants $-3,672$ C. cyanus and 3,744 S. noctiflora. The 26 combinations were chosen based on a response-surface design (Figure 1). In manipulated plant competition experiments, this type of design is recommended, whereby both density and proportions are varied to cover a wide array of realistic conditions in natural populations (Inouye 
2001). Plants of each species were grown individually, in six densities of monoculture, and in 14 different densities and proportions relative to one another (Table 1).

C. cyanus seeds were obtained from commercial seed suppliers (OSC seeds, jubilee gem variety of bachelor's button). S. noctiflora seeds were shipped to Environment Canada and Climate Change from Denmark, where these seeds were collected from wild populations in 1995 in Flakkebjerg, Denmark and propagated in the greenhouses in 2007. All seeds were surface sown in small trays containing enriched soil (88\% Pro-mix BX and $12 \%$ sand, plus clay and calcium carbonate) and placed in the greenhouses. After emergence, seedlings of both species were transplanted following standardized arrangements for each combination into opaque plastic containers (39L x $28 \mathrm{~W} \times 12 \mathrm{H} \mathrm{cm}$ ), containing the same enriched soil mixture. Pots were randomly placed in the greenhouse units by replicate, with a fourth unit for half a dozen plants of each replicate which did not fit in the other units. Plants were watered daily.

Plants were sprayed at the juvenile 6-8 leaf stage with Glyphos (active ingredient glyphosate, formulated as an isopropylamine salt, Cheminova Inc.). Three doses were used for each combination: control (no herbicide spray) and 14.4 and $72.0 \mathrm{~g}$ a.e/ha. This is equivalent to $1 \%$ and $5 \%$ of the maximum recommended label rates of glyphosate in agriculture (1440 g a.e./ha), and simulates herbicide drift. Plants were sprayed using a track spray booth (DeVries Manufacturing, $\mathrm{MN}$ ) equipped with a Teejet $8002 \mathrm{E}$ flat-fan spray nozzle, which delivers $7.75 \mathrm{~mL} / \mathrm{m}^{2}$ at a pressure of $206.84 \mathrm{kPa}$.

Each pot was assigned a numerical ID tag with treatment randomly assigned so that the observer would be unaware of the dose during assessments in order to prevent bias. For all combinations except the individual plants, a sample of four plants of each 
species was used to represent the pot for assessments throughout the experiment. These four plants were chosen randomly before assessments began, but were from positions in the centre of the pot as to avoid edge effects. This gave a total sample size of 1,387 plants.

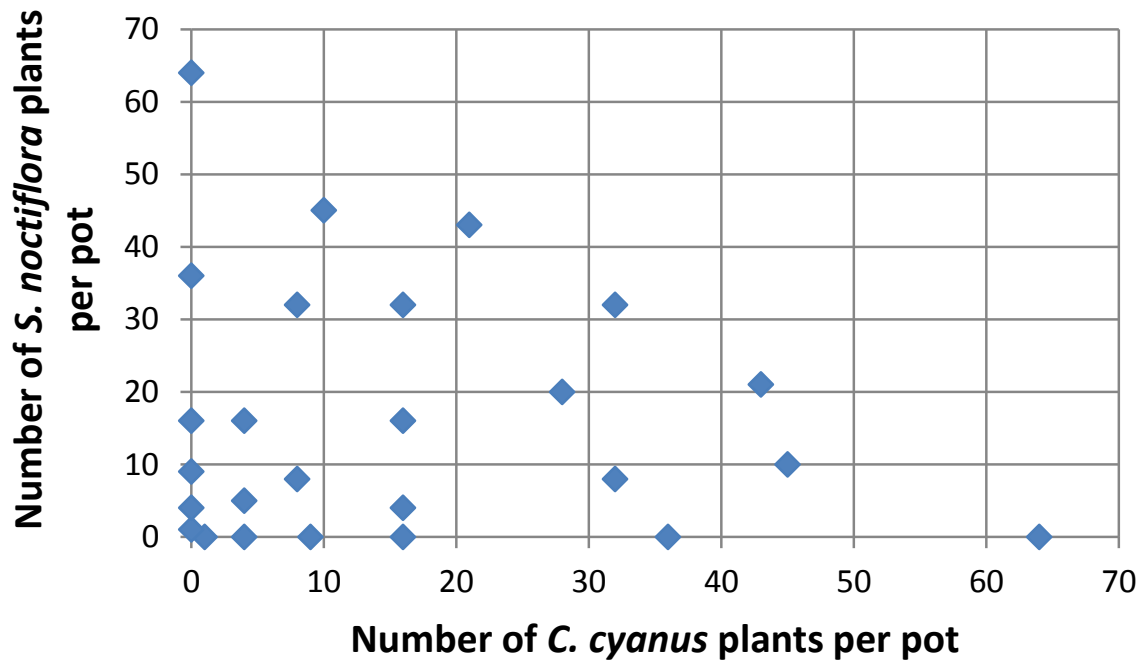

Figure 1. Compositions of the densities and proportions in pots used to study herbicide drift and competition between $C$. cyanus and $S$. noctiflora. 
Table 1. Experimental Design

\begin{tabular}{|c|c|c|c|c|c|c|c|c|}
\hline \multirow{2}{*}{$\begin{array}{l}\text { Species and } \\
\text { mixture type }\end{array}$} & \multicolumn{2}{|c|}{ Pot density } & \multirow{2}{*}{$\begin{array}{l}\text { Phenological } \\
\text { stage at spray }\end{array}$} & \multirow[t]{2}{*}{ Herbicide } & \multirow[t]{2}{*}{ Doses } & \multicolumn{2}{|c|}{ Endpoints } & \multirow{2}{*}{$\begin{array}{c}\text { Replicate } \\
\text { s }\end{array}$} \\
\hline & & & & & & Vegetative & Reproductive & \\
\hline $\begin{array}{c}\text { C. cyanus } \\
\text { (monoculture) }\end{array}$ & $\begin{array}{l}1 \\
4 \\
9\end{array}$ & $\begin{array}{l}16 \\
36 \\
64\end{array}$ & \multirow{3}{*}{$\begin{array}{c}\text { Vegetative } \\
(6-8 \text { leaf stage })\end{array}$} & \multirow{3}{*}{$\begin{array}{l}\text { Glyphosate } \\
\text { (1440 g } \\
\text { a.e/ha) }\end{array}$} & \multirow{3}{*}{$\begin{array}{l}0 \% \\
1 \% \\
5 \%\end{array}$} & $\begin{array}{l}\text { Maximum height } \\
\text { Maximum diameter } \\
\text { Visual assessments }\end{array}$ & $\begin{array}{l}\text { Time to first Flower } \\
\text { Duration of flowering } \\
\text { Number of flowers } \\
\text { Seed weight } \\
\text { Number of seeds } \\
\text { Proportion of seeds } \\
\quad \text { germinated }\end{array}$ & \multirow{3}{*}{3} \\
\hline $\begin{array}{l}\text { S. noctiflora } \\
\text { (monoculture) }\end{array}$ & $\begin{array}{l}1 \\
4 \\
9\end{array}$ & $\begin{array}{l}16 \\
36 \\
64\end{array}$ & & & & $\begin{array}{l}\text { Biomass } \\
\text { Visual assessments }\end{array}$ & & \\
\hline $\begin{array}{c}\text { 2-species } \\
\text { mixtures } \\
\text { (C. cyanus/ } \\
\text { S. noctiflora) }\end{array}$ & $\begin{array}{c}4 / 5 \\
4 / 16 \\
8 / 8 \\
8 / 32 \\
16 / 4 \\
16 / 1 \\
32 / 8\end{array}$ & $\begin{array}{l}32 / 32 \\
10 / 45 \\
16 / 32 \\
28 / 20 \\
45 / 10 \\
43 / 21 \\
21 / 43\end{array}$ & & & & $\begin{array}{l}\text { Both species } \\
\text { measured using } \\
\text { species-specific } \\
\text { endpoints as listed } \\
\text { above }\end{array}$ & $\begin{array}{l}\text { Both species measured } \\
\text { using species-specific } \\
\text { endpoints as listed above }\end{array}$ & \\
\hline
\end{tabular}




\section{Vegetative assessments}

Visual symptoms of herbicidal effects were assessed once a week for the duration of the experiment using a scale ranging from 0 (no effects) to 9 (plant death). These are commonly used in toxicology to examine effects such as chlorosis or necrosis, and are quantified in Appendix 1. These assessments were conducted by the same observer each week. Height and diameter were measured each week, until the majority $(>70 \%)$ of the plants were no longer growing. Although these measurements are less sensitive than biomass, they are non-destructive and can be measured over time. As most S. noctiflora did not flower over the course of the experiment, these plants were harvested for above ground biomass after six months, when the $C$. cyanus plants began dying after flowering. Although not part of the original experimental design, this was the only data that could be collected for $S$. noctiflora. All healthy $S$. noctiflora plants were cut at the soil surface and bagged individually. They were then dried in a drying oven at approximately $70^{\circ} \mathrm{C}$ for 72 hours prior to weighing. Dry weight was then recorded for each plant using a precision scale of $0.001 \mathrm{mg}$ accuracy (Denver Instruments, NY).

\section{Reproductive assessments}

Reproductive endpoints used during the experiment are listed in Table 1. When plants began flowering, bumblebee pollinators (Bombus impatience $\mathrm{Cr}$.) were released into all greenhouse units to pollinate the two species. Plants were examined each day for the beginning of flowering, and after flowering began the number of flowers and seedheads were counted twice a week. To prevent seed losses from shedding, ripe fruit/dried seedheads were cut and counted throughout the experiment and put in labeled envelopes. 
The seeds from each plant were counted using a seed counter (Elmor C1, Switzerland) to give a total seed count for each plant. One hundred seeds from each plant were then randomly selected and weighed using a precision scale of $0.001 \mathrm{mg}$ accuracy (Denver Instrument, NY). The germination of the 100 seeds was then tested in the growth chamber at $20^{\circ} \mathrm{C}$, a 16/8 L:D photoperiod and PAR) $189 \mathrm{~mol} \mathrm{~m}^{-1} \mathrm{~s}^{-2}$. The 100 seeds were placed in a labeled $100 \times 15 \mathrm{~mm}$ petri dish on three pieces of $9.0 \mathrm{~cm}$ filter paper $(\mathrm{P} 8$ creped, Fisher Scientific, Ottawa, $\mathrm{ON}$ ) moistened with $4 \mathrm{~mL}$ of a $0.2 \% \mathrm{KNO}_{3}$ solution to break seed dormancy. The petri dishes were checked daily and the seeds that had germinated were counted and removed from the dish. This was done for only the $C$. cyanus plants, as no S. noctiflora plants produced seeds. In cases where a plant had fewer than 100 seeds, all of the seeds from the plant were used for weighing and germination tests. After two weeks, if there were four consecutive days with no germination, the test was concluded for that dish. From this, the proportion of seeds that germinated and the speed of germination could be determined. Speed of germination was calculated using an adjusted formula from Allaie et al. (2006): $\Sigma\left(\mathrm{N}_{1} / 1+\mathrm{N}_{2} / 2+\mathrm{N}_{3} / 3+\ldots . .+\mathrm{N}_{i / i}\right)$, where $\mathrm{N}_{1}$ is number of seeds germinated on day $1, \mathrm{~N}_{2}$ is number of seeds germinated on day 2 , etc. and $\mathrm{N}_{i}$ is the number of seeds germinated on day $i$.

\section{Statistical analysis}

\section{Competition model}

The competition model was used to determine if the competitive interactions between species or conspecifics were altered. The values for the four plants sampled were averaged to give a single value per pot. These pot averages were used for analysis. The effect of the herbicide doses on the vegetative and reproductive endpoints of the two 
competing species was modelled by a generalization of a discrete hyperbolic competition model. This type of curve only fits well for the data of three of the endpoints measured, and therefore only S. noctiflora biomass and C. cyanus flower and seed production could be modelled. Based on the experimental data, the model predicts the influence of the herbicide on the competitive interactions between conspecifics as well as possible changes of the competitive effect that each species has on the other. The hyperbolic response function is flexible, and has been shown to fit plant competition data well (Law \& Watkinson 1987; Cousens 1991). This type of model is necessary in order to incorporate the non-linear effects of density (Damgaard 2008). We assume a linear effect of the herbicide on the competitive interaction and on the biomass and seed production.

For $S$. noctiflora (sn) biomass, the equation is as follows:

$\left.\left.\mu_{\mathrm{sn}}=\left\{a_{\mathrm{sn}}+\alpha_{\mathrm{sn}} \mathrm{h}\right)+\sigma_{\mathrm{sn}}+\beta_{\mathrm{sn}} \mathrm{h}\right)\left[\mathrm{x}_{\mathrm{sn}}+\left(c_{\mathrm{cc}}+\gamma_{\mathrm{cc}} \mathrm{h}\right) \mathrm{x}_{\mathrm{cc}}\right]^{d \mathrm{sn}}\right\}^{-1 / / \mathrm{sn}}$

and for C. cyanus (cc) seed production:

$\left.\left.\mu_{\mathrm{cc}}=\left\{a_{\mathrm{cc}}+\alpha_{\mathrm{cc}} \mathrm{h}\right)+\sigma_{\mathrm{cc}}+\beta_{\mathrm{cc}} \mathrm{h}\right)\left[\mathrm{x}_{\mathrm{cc}}+\left(c_{\mathrm{sn}}+\gamma_{\mathrm{sn}} \mathrm{h}\right) \mathrm{x}_{\mathrm{sn}}\right]^{\mathrm{dcc}}\right\}^{-1 / f \mathrm{cc}}$

where $\mu$ is the predicted response, $h$ is the level of the herbicide treatment, $\mathrm{x}$ is the density of the plant species, and $\mathrm{d}$ and $\mathrm{f}$ are shape parameters of the response function of the plant species that are assumed to be independent of the herbicide treatment (Damgaard 2003; Damgaard et al. 2008).

The biomass/flower-seed production of the species at low density and no herbicide in monoculture is measured by $a$, while 6 is the biomass/flower-seed production per area at high density in monoculture with no herbicide, with $\alpha$ and $\beta$ measuring the effect of the herbicide treatment. The competition coefficient with no herbicide is measured by $c$, and $\gamma$ measures the effect of the herbicide on competitive 
ability. Analogous to the Lotka-Volterra model, the competition coefficient is interpreted as the effect of species 1 on species 2 , measured in species 2 equivalents. This means that the term $\mathrm{c}^{+} \gamma \mathrm{h}$ measures the effect of interspecific competition relative to intraspecific competition (Damgaard et al. 2008).

For an example, consider the biomass of $S$. noctiflora. The $a+\alpha$ h is measuring biomass in low density monoculture, where $a$ is the biomass of the control, and $\alpha \mathrm{h}$ considers the effect of the herbicide. Similarly, $b+\beta \mathrm{h}$ is the biomass in low density monoculture, where $b$ is the biomass of the control and $\beta$ h considers the effect of the herbicide. The last bracket $\mathrm{x}_{\mathrm{sn}}+(c+\gamma \mathrm{h}) \mathrm{x}_{\mathrm{cc}}$ looks at interspecific competition, where the $\mathrm{x}$ values are the densities of the two species. If we are looking at the biomass of $S$. noctiflora then this is looking at the competitive effect of $C$. cyanus on the biomass. $C$ the competitive effect of C. cyanus on S. noctiflora biomass with no herbicide, and $\gamma \mathrm{h}$ considers the effect of the herbicide.

The model was fitted to the average biomass measurements to evaluate effects on S. noctiflora, and was fitted to the average flower or seed production to evaluate effects on $C$. cyanus. The parameters $a, b, \mathrm{~d}$ and $\mathrm{f}$ were reparameterized with the exponential function in order to avoid negative values. To determine if there was a significant effect of the herbicide, $\alpha, \beta$ and $\gamma$ are set to zero in that order (Damgaard et al. 2008). Modelling was performed by Christian Damgaard, Aarhus University, Denmark.

\section{Other endpoints}

As the hyperbolic curve of the competition model only fits the biomass and flower and seed production data, other statistical analyses were explored for the 
remaining endpoints: height, diameter, days to first flower, duration of flowering, seed weight, and proportion of germinated seeds and speed of germination, using the pot averages of the four plants sampled. As plants can be tested individually in ERA, these endpoints were used to examine if plants in competition responded differently than individually potted plants. Due to the non-linear effects of densities in the combinations chosen to fit the model a GLM could not be used to determine interacting effects between dose and density. Instead, ANOVAs and Kruskal-Wallis tests in Systat (version 13) were used to compare if the degree of difference in response between the plants in competition and the individual plants vary by dose. This was done by calculating the response of the plants in competition relative to the response of the individual plant at the same dose. ANOVAs and Kruskal-Wallis were then used to compare these relative values between

doses. A false discovery rate of 0.1 (using the Benjamini-Hochberg procedure from Benjamini \& Hochberg 1995) was used to correct for multiple comparisonsThis was done separately for monocultures and two-species mixtures.

\section{Chapter 3: Results}

\section{Visual assessments}

Glyphosate induced a number of obvious visual changes regardless of density, but these changes were slightly worse in the more dense pots. The most obvious visual changes were chlorosis and reductions in size (for instance, refer to Figures 1 and 2 in Appendix 1). These effects occurred most strongly during the first month after spray, and more individuals of the $5 \%$ dose were affected for both species. However, the damaging vegetative effects generally decreased over time after the first month, for both species. 


\section{Density effects}

For all endpoints, it was evident that density effects occurred. As density increased, plants were negatively affected, in all three doses: height and diameter decreased (Figures 2 and 3); time to flowering increased and duration of flowering decreased (Figures 4 and 5); seed weight, the proportion of germinated seeds, and the speed of germination decreased (Figures 6-8); biomass decreased (Figure 9); and the number of flowers (Figure 10) and the number of seeds decreased (Figure 11) with increasing density. These density effects are not linear.

\section{Height, diameter, duration and time to first flowering, seed weight, and germination}

It was found that glyphosate dose had no overall effect on any of the endpoints, in either individual plants, or monocultures or two-species mixtures (Table 2). However, for three of these endpoints, there were relative differences in the two-species mixtures: the responses of plants in competition relative to the individual plants sprayed at the same dose were different than the responses of the control plants in competition relative to the individual control plants (Table 3). This was the case for maximum height (Figure 2, $\mathrm{F}_{2,123}=5.173, \mathrm{p}=0.007$ ), days to flowering (Figure $3, \chi^{2}=37.195, \mathrm{df}=2, \mathrm{p}<0.001$ ), and for seed weight (Figure $6, \chi^{2}=27.068, \mathrm{df}=2, \mathrm{p}<0.001$ ). However this was only the cases for the two-species mixtures. C. cyanus plants competing with $S$. noctiflora did not respond the same way to herbicides as the individual plants, but those only competing with conspecifics did respond the same as the individual plants.

The plants in the two-species mixtures were all very similar in height regardless of density type (individual, monocultures or 2-species mixtures) (Figure 12). This lead to significant relative differences.. Dosed plants in competition were significantly shorter 
relative to the dosed individual plants when compared to the relative differences between the controls (Figure 2).

For number of days until flowering, there were differences for the $1 \%$ and $5 \%$ doses. The plants in interspecific competition dosed with $1 \%$ experience a larger delay in flowering relative to the individual plants than do the controls ( $p=0.001$, Figure 13). But for the $5 \%$ plants, the controls experience the larger delay in flowering when in competition - the dosed plants in competition flower around the same time as the dosed individual plant ( $\mathrm{p}=0.001$, Figure 13).

Regarding seed weight, the plants in competition sprayed with 5\% glyphosate produced seeds similar in weight to those produced by the individual plants sprayed with $5 \%$. This did not occur in the control, as plants in competition produced seeds much lower in weight relative to the individual control, so that again there were relative differences between individual plants and plants in competition at the same dose $(\mathrm{p}<0.001$, Figure 14).

\section{Competition model}

The hyperbolic curve was fit to biomass measurements and counts of flowers and seeds in order to understand the effects of glyphosate on competition. The effects of glyphosate and intra- and interspecific competition on the biomass of S. noctiflora are shown in Figure 9, the effects on C. cyanus flowering are shown in Figure 10, and the effects on C. cyanus seed production are shown in Figure 11. The density effects are evident in both monoculture and the two-species mixtures, as described previously (and statistically significant, parameters $a$ and 6 in Tables 4 and 5), but dose effects can be subtle. 
Both $\alpha$ and $\beta$ were significant for the seed production of C. cyanus, but not for flower production nor for the biomass of $S$. noctiflora (Tables 4 and 5). This demonstrates that glyphosate affected C. cyanus's ability to compete with conspecifics at both low and high densities while producing seeds. However S. noctiflora's ability to compete with conspecifics was unaltered.

When examining the two-species mixtures for interspecific competition with no herbicide (the competition coefficient, c), it is shown that C. cyanus was a stronger competitor than $S$. noctiflora- the effect of $C$. cyanus on $S$. noctiflora is greater than the effect of $S$. noctiflora on itself (tables 4 and 5, c >1), and the effect of S. noctiflora on $C$. cyanus is less than the effect of C. cyanus on itself (tables 4 and $5, c<1$ ). On the graphs, this is seen where C. cyanus plants perform more poorly in pots containing more conspecifics compared to pots of equivalent densities but fewer of its conspecifics (more S. noctiflora). For instance, comparing combinations $16 / 0$ with $8 / 8$, or $64 / 0$ with $21 / 43$, $32 / 32$ and 43/21 for flower (Figure 9) and seed production (Figure 10).

With herbicide exposure, the competitive interactions between the two species were altered. The competitive effect of C. cyanus on S. noctiflora $\left(\gamma_{\mathrm{cc}}\right)$ biomass was weakened by glyphosate (Tables 4 and 5), as was S. noctiflora's competitive effect on $C$. cyanus's $\left(\gamma_{\mathrm{sn}}\right)$ seed production (Table 5). This means that while C. cyanus could not suppress the growth of S. noctiflora as well when exposed to the herbicide, S. noctiflora was not able to suppress the seed production of $C$. cyanus as efficiently either. These negative impacts on competitive effects were, however, more pronounced for $S$. noctiflora, as shown by the more negative parameter values. However, S. noctiflora's 
ability to suppress the flowering of $C$. cyanus was unchanged by the herbicide $\left(\gamma_{\mathrm{sn}}\right.$ in Table 4).

\section{Relationships between endpoints}

There were also expected relationships between variables: plants that took longer to begin flowering flowered for less time (Figure 15); plants that took longer to begin flowering produced fewer flowers (Figure 16); plants that produced more flowers produced more seeds (Figure 17); the proportion of seeds germinating increased with seed weight (Figure 18); and speed of germination increased with seed weight (Figure 19). The differences by density are also seen, with plants in the lower density pots generally doing better (for instance, less time to begin flowering and more flowers produced). Many of the relationships do not appear to vary by dose, except for the relationship between flower and seed production (Figure 17): as dose increases, plants produce fewer seeds per flower. The trend is approaching significance $\left(\mathrm{F}_{2,175}=2.880\right.$, $\mathrm{p}=0.059)$. 

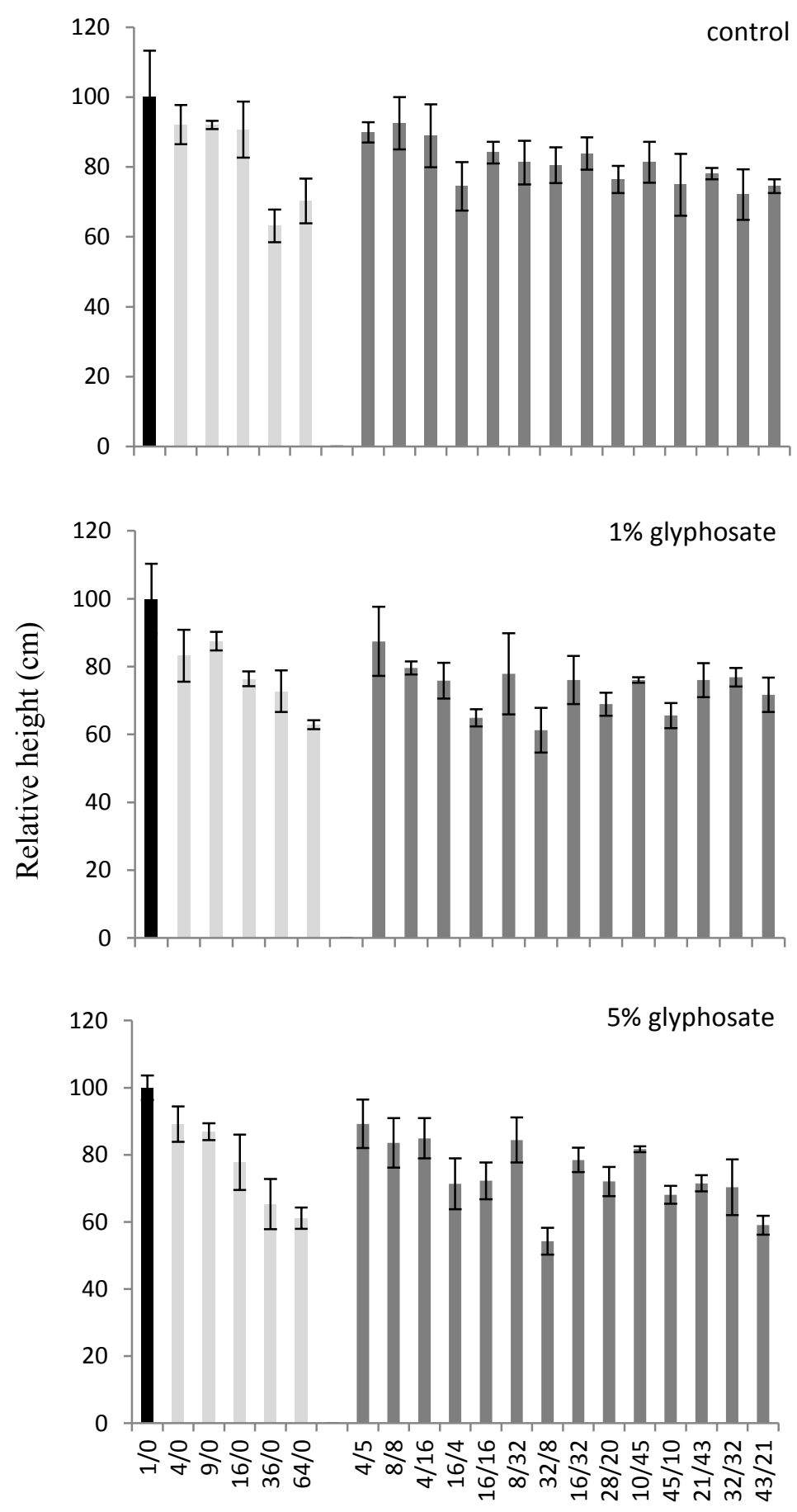

Pot combination (no. of C. cyanus/no. of S. noctiflora)

Figure 2. Average maximum height with standard error of C. cyanus in competition with conspecifics and $S$. noctiflora in various mixtures, sprayed with different doses of the herbicide glyphosate. Black is the individually potted plants, light grey the monocultures, dark grey the two-species mixtures. Values for monocultures and two-species mixtures were calculated relative to the individual plant. X-axis increases in density towards the right for the groups, but note the varying proportions of the two species. 

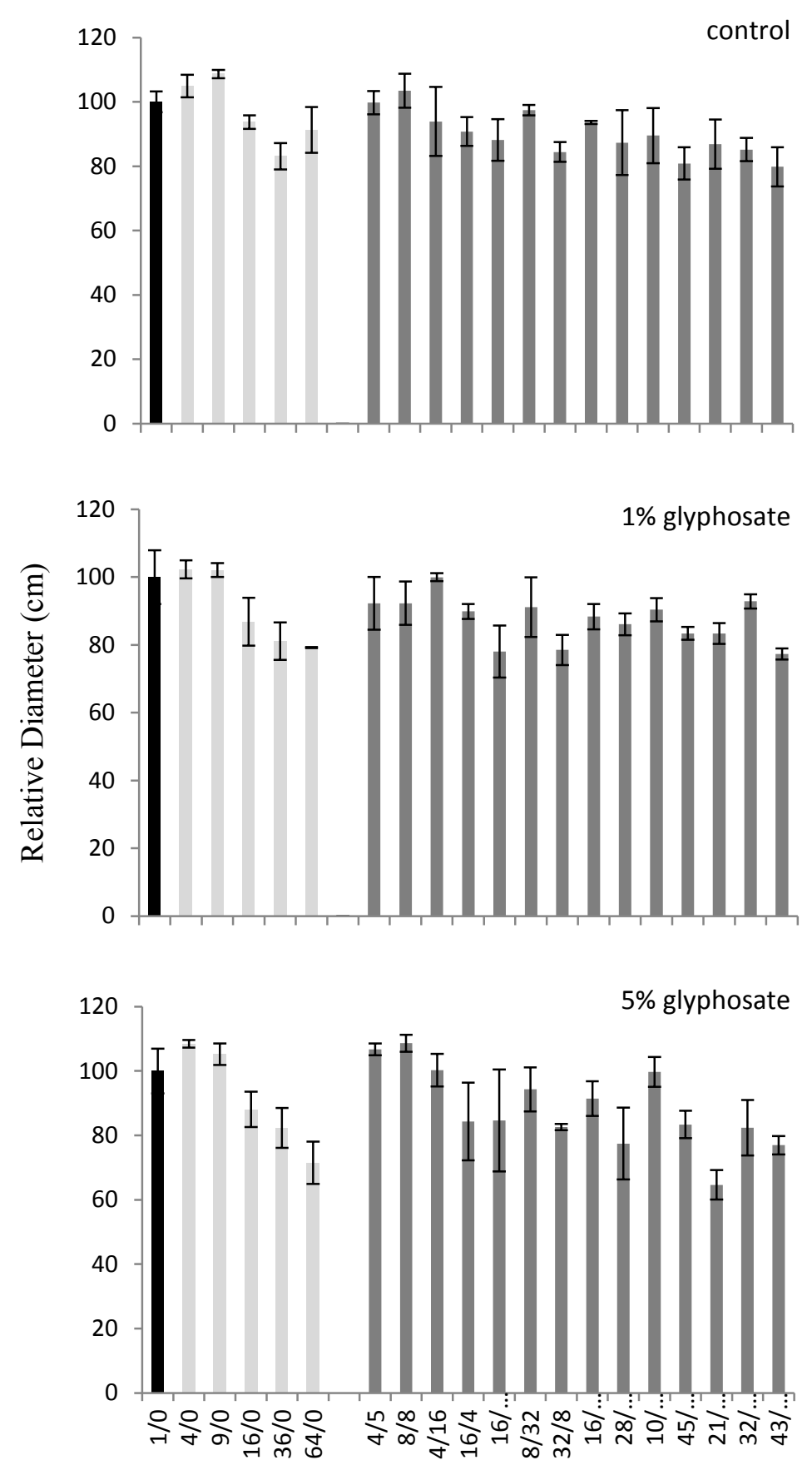

Pot combination (no. of C. cyanus/no. of S. noctiflora)

Figure 3. Average maximum diameter with standard error of $C$. cyanus in competition with conspecifics and $S$. noctiflora in various mixtures, sprayed with different doses of the herbicide glyphosate. Black is the individually potted plants, light grey the monocultures, dark grey the two-species mixtures. Values for monocultures and two-species mixtures were calculated relative to the individual plant. X-axis increases in density towards the right for the groups, but note the varying proportions of the two species. 

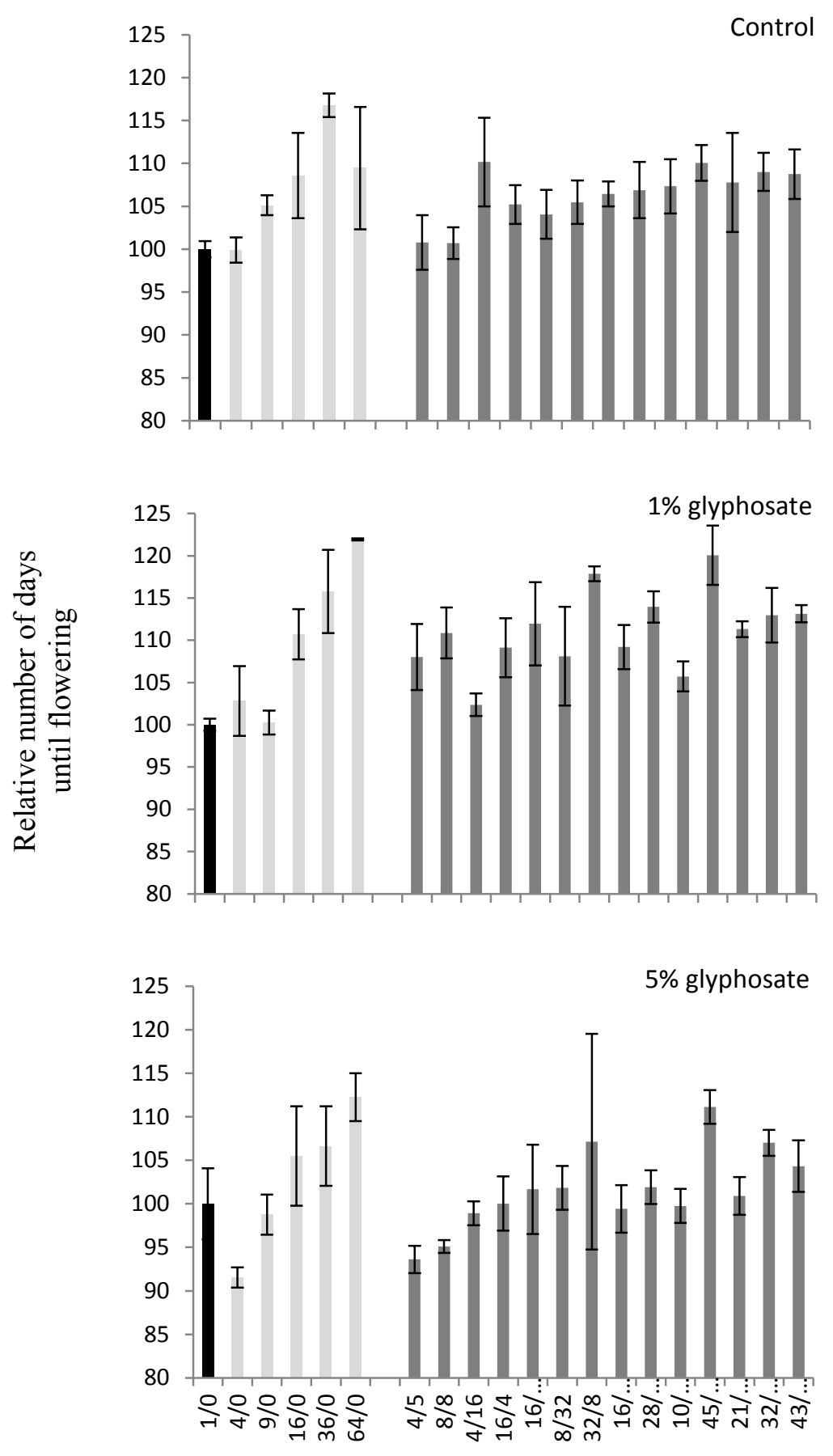

Pot combination (no. of C. cyanus/no. of S. noctiflora)

Figure 4. Average number of days until flowering with standard error of $C$. cyanus in competition with conspecifics and $S$. noctiflora in various mixtures, sprayed with different doses of the herbicide glyphosate. Black is the individually potted plants, light grey the monocultures, dark grey the two-species mixtures. Values for monocultures and two-species mixtures were calculated relative to the individual plant. $\mathrm{X}$-axis increases in density towards the right for the groups, but note the varying proportions of the two species. Also note $\mathrm{x}$-acis starts at 80 . 

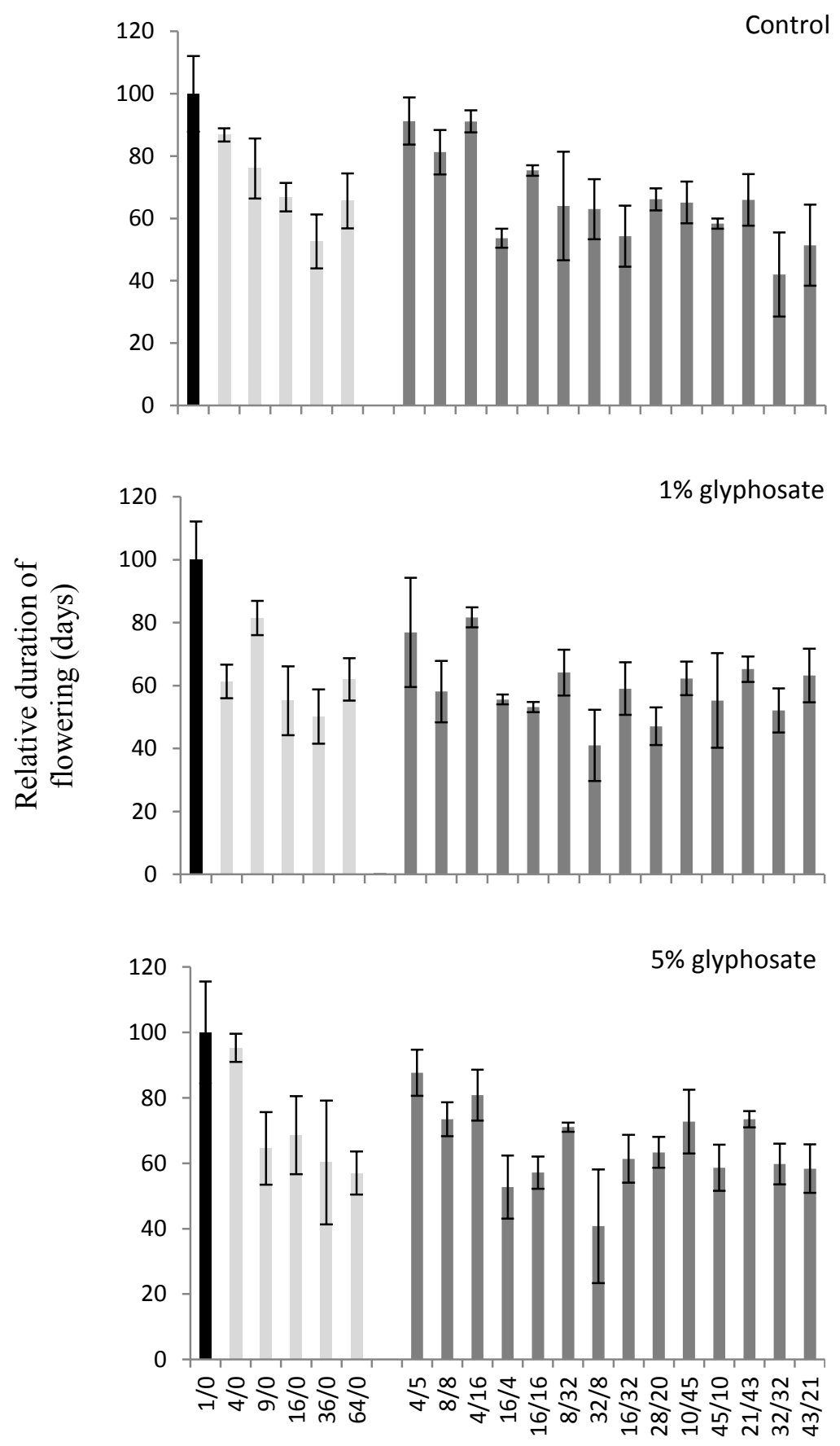

Pot combination (no. of C. cyanus/no. of S. noctiflora)

Figure 5. Average duration of flowering with standard error of C. cyanus in competition with conspecifics and S. noctiflora in various mixtures, sprayed with different doses of the herbicide glyphosate. Black is the individually potted plants, light grey the monocultures, dark grey the two-species mixtures. Values for monocultures and two-species mixtures were calculated relative to the individual plant. X-axis increases in density towards the right for the groups, but note the varying proportions of the two species. 

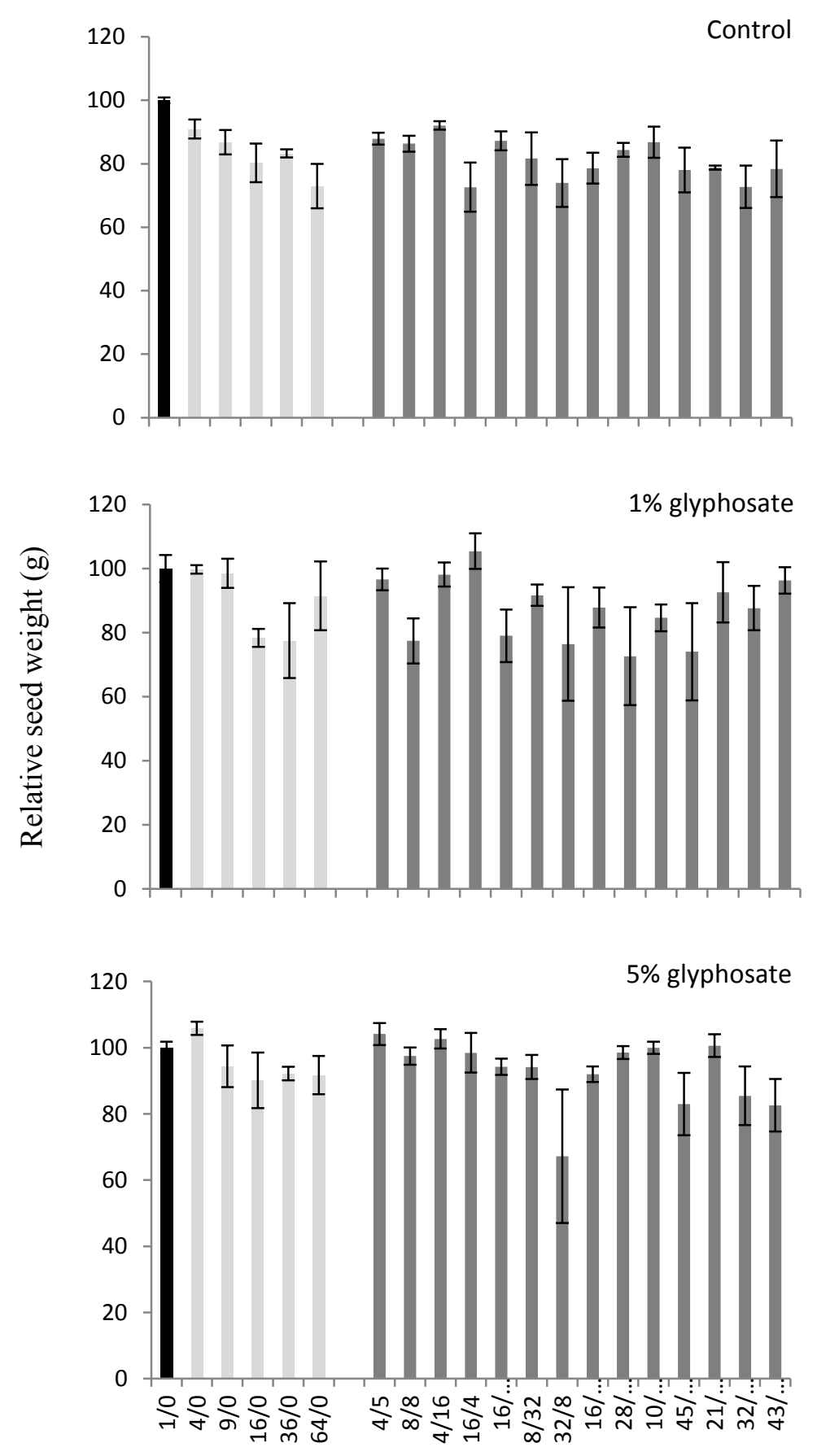

Pot combination (no. of C. cyanus/no. of S. noctiflora)

Figure 6. Average seed weight with standard error of C. cyanus in competition with conspecifics and $S$. noctiflora in various mixtures, sprayed with different doses of the herbicide glyphosate. Black is the individually potted plants, light grey the monocultures, dark grey the two-species mixtures. Values for monocultures and two-species mixtures were calculated relative to the individual plant. X-axis increases in density towards the right for the groups, but note the varying proportions of the two species. 

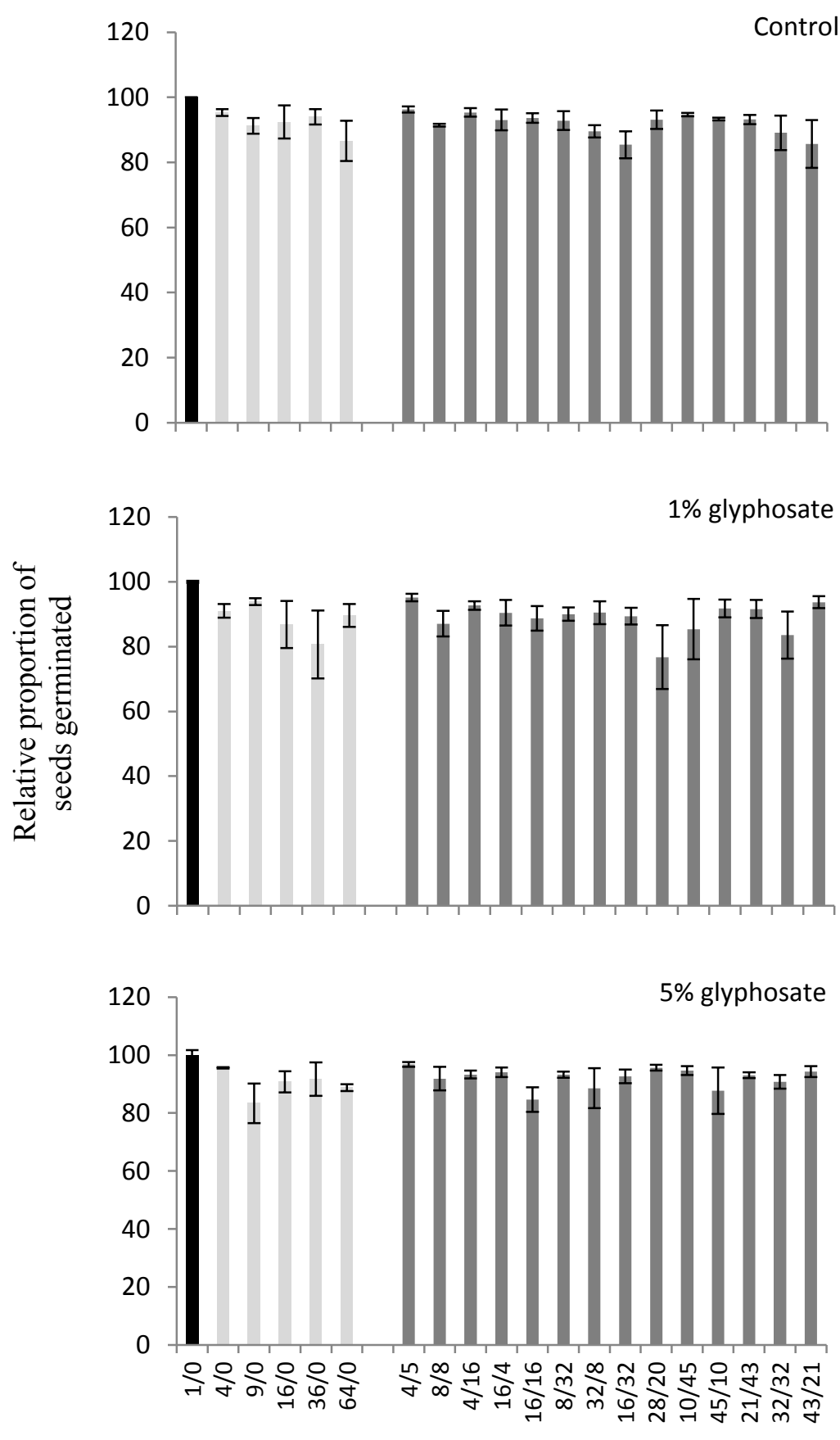

Pot combination (no. of C. cyanus/no. of S. noctiflora)

Figure 7. Average proportion of seeds germinated with standard error of $C$. cyanus in competition with conspecifics and S. noctiflora in various mixtures, sprayed with different doses of the herbicide glyphosate. Black is the individually potted plants, light grey the monocultures, dark grey the two-species mixtures. Values for monocultures and two-species mixtures were calculated relative to the individual plant. $\mathrm{X}$-axis increases in density towards the right for the groups, but note the varying proportions of the two species. 

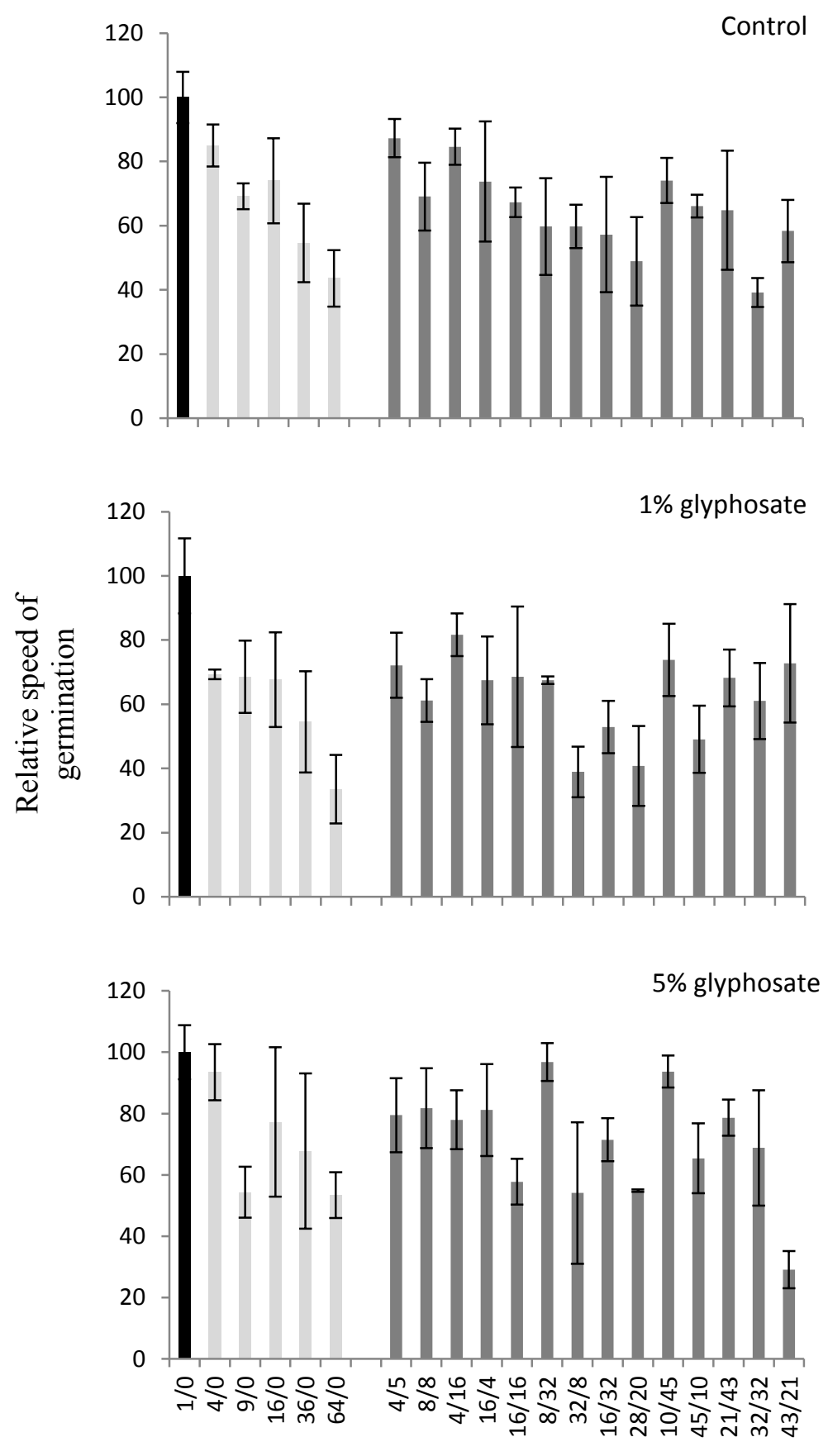

Pot combination (no. of C. cyanus/no. of S. noctiflora)

Figure 8. Average speed of germination with standard error of C. cyanus in competition with conspecifics and S. noctiflora in various mixtures, sprayed with different doses of the herbicide glyphosate. Black is the individually potted plants, light grey the monocultures, dark grey the two-species mixtures. Values for monocultures and two-species mixtures were calculated relative to the individual plant. X-axis increases in density towards the right for the groups, but note the varying proportions of the two species. 

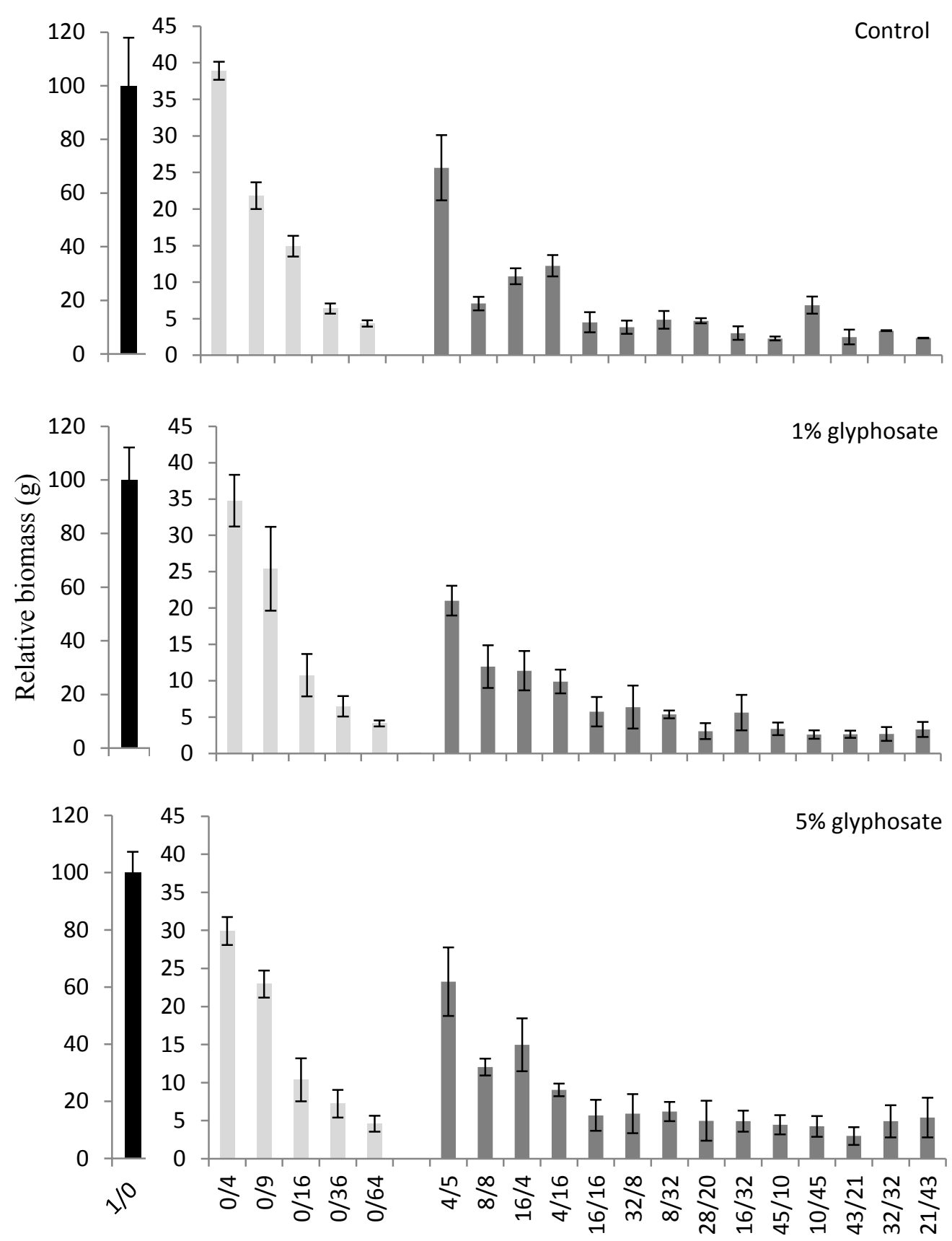

Pot combination (no. of C.cvanus/no. of S.noctiflora)

Figure 9. Average biomass and standard error of $S$. noctiflora when in competition with conspecifics and C. cyanus in various mixtures at different doses of the herbicide glyphosate. Black is the individually potted plants, light grey the monocultures, dark grey the two-species mixtures. Values for monocultures and two-species mixtures were calculated relative to the individual plant. X-axis increases in density towards the right for the groups, but note the varying proportions of the two species. Values for monocultures and two-species mixtures were calculated relative to the individual plant. 

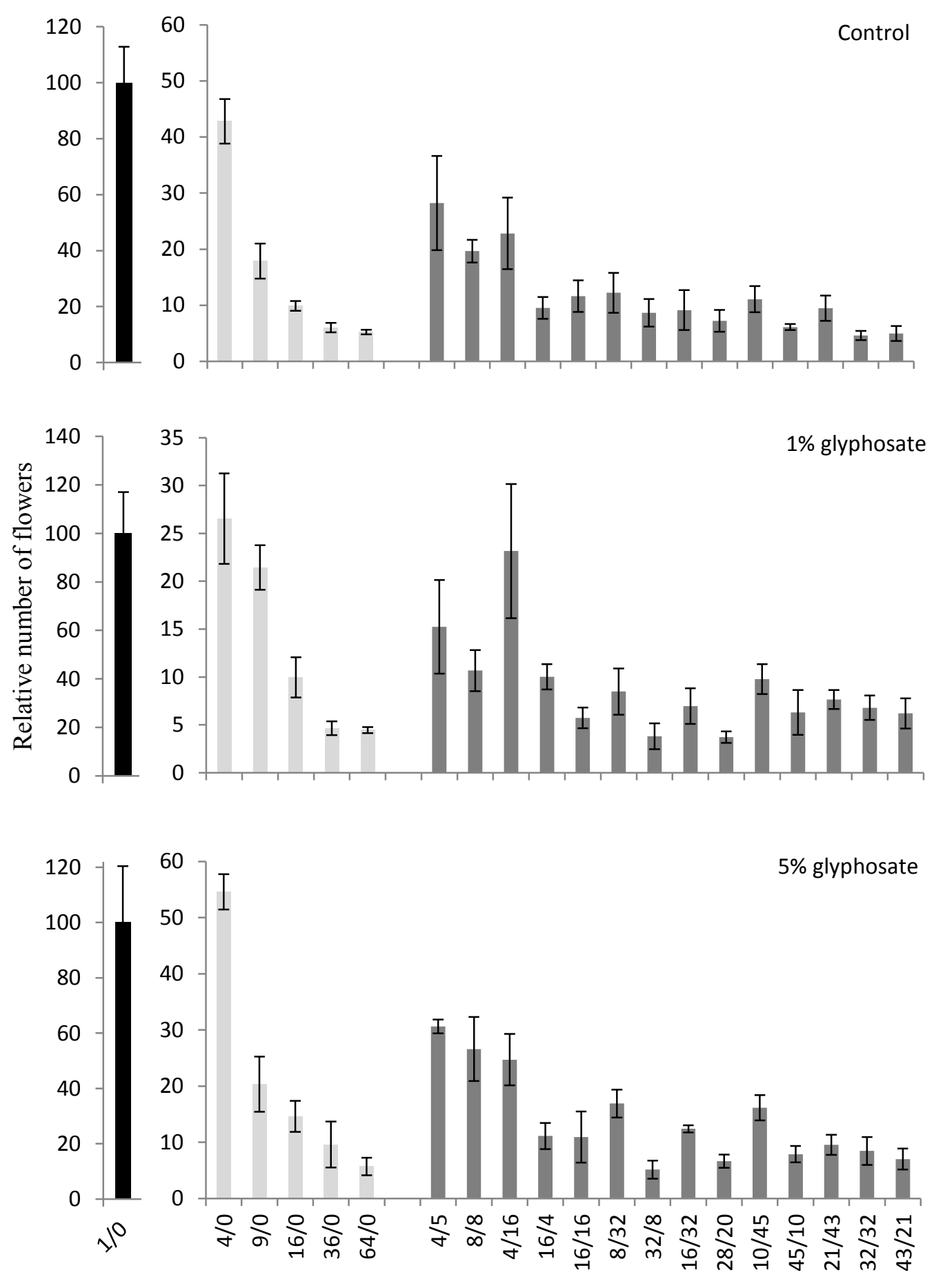

Pot combination (no. of C.cvanus/no. of S.noctiflora)

Figure 10. Average number of flowers and standard error produced by C. cyanus when in competition with conspecifics and $S$. noctiflora in various mixtures at different doses of the herbicide glyphosate. Black is the individually potted plants, light grey the monocultures, dark grey the two-species mixtures. Values for monocultures and two-species mixtures were calculated relative to the individual plant. 

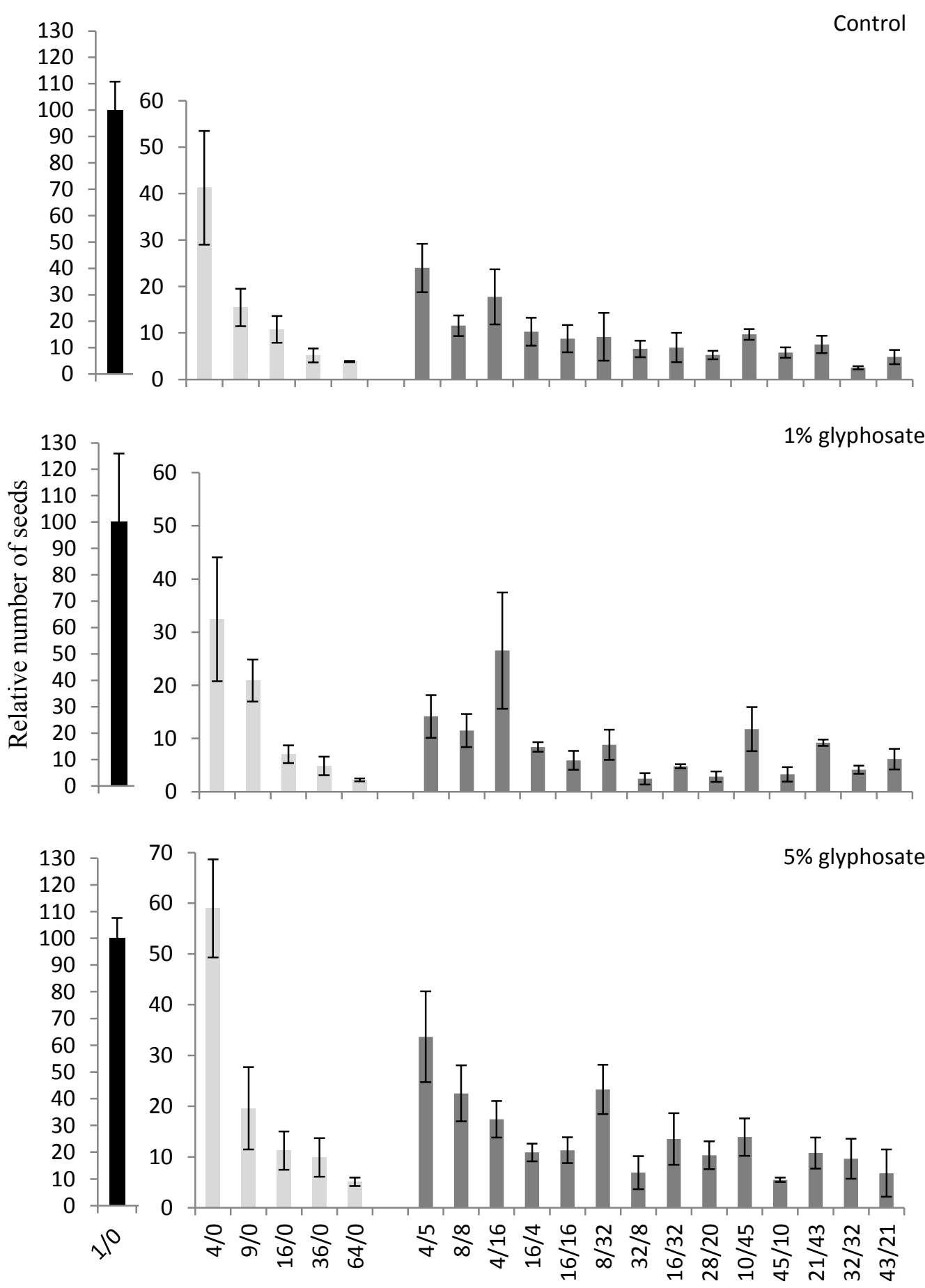

Pot combination (no. of C.cyanus/no. of S.noctiflora)

Figure 11. Average number of seeds and standard error produced by $C$. cyanus when in competition with conspecifics and $S$. noctiflora in various mixtures at different doses of the herbicide glyphosate. Black is the individually potted plants, light grey the monocultures, dark grey the two-species mixtures. Values for monocultures and two-species mixtures were calculated relative to the individual plant. 


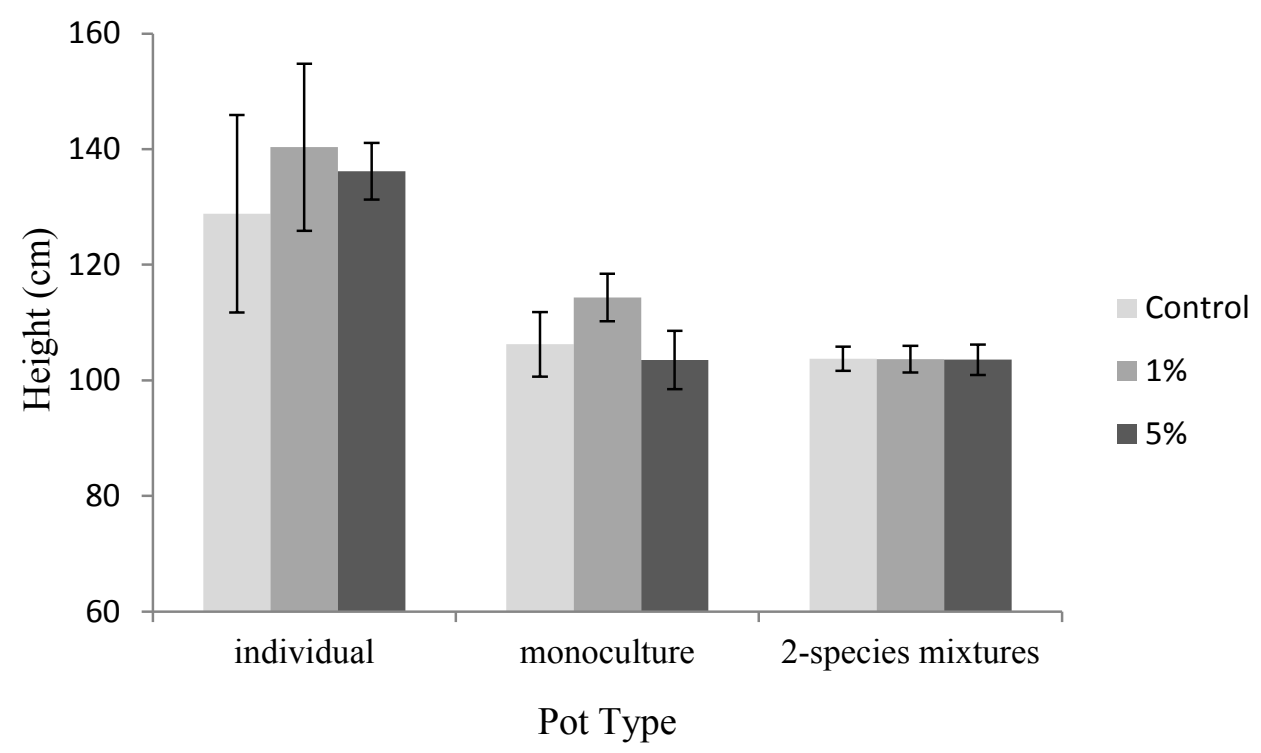

Figure 12. Height of C. cyanus in monocultures and mixtures with $S$. noctiflora at different doses of glyphosate.

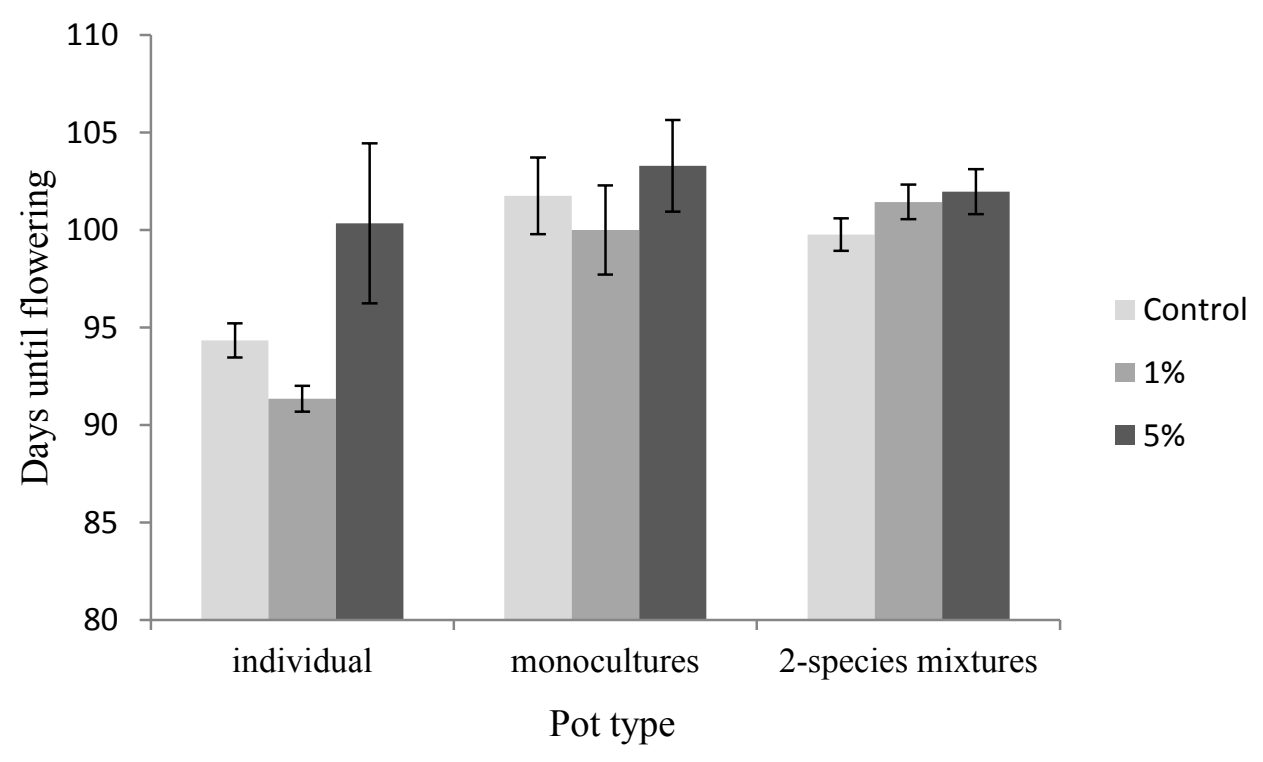

Figure 13. Days until flowering of C. cyanus in monocultures and mixtures with $S$. noctiflora at different doses of glyphosate. 


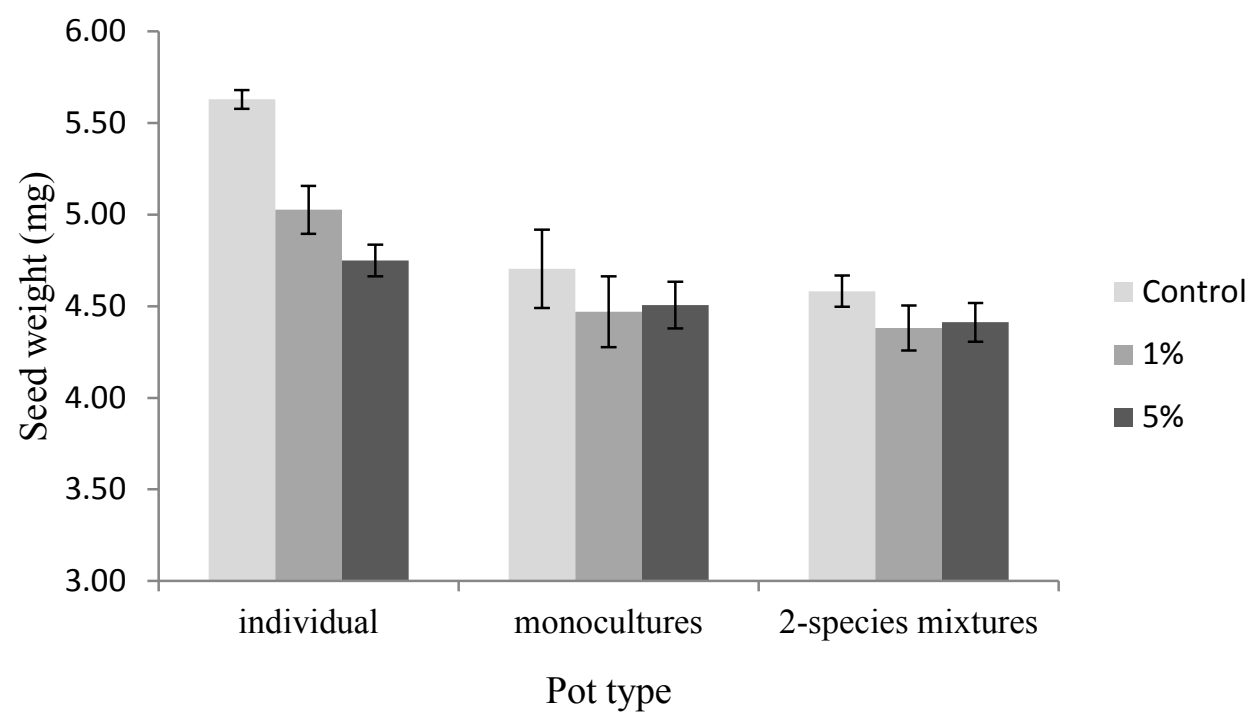

Figure 14. Seed weight of $C$. cyanus seeds in monocultures and mixtures with $S$. noctiflora at different doses of glyphosate. 
Table 2. Results of statistical analysis for the effect of glyphosate dose on various endpoints.

\begin{tabular}{|c|c|c|c|c|}
\hline Variable & pot type & $\begin{array}{c}\text { ANOVA F/ } \\
\text { Kruskal-Wallis } \chi^{2}\end{array}$ & df & p-value \\
\hline \multirow{3}{*}{ height } & Individual & 0.194 & 2,6 & 0.828 \\
\hline & monoculture & 0.291 & 2,49 & 0.749 \\
\hline & 2-species mix & 0.368 & 2,123 & 0.693 \\
\hline \multirow{3}{*}{ diameter } & Individual & 0.124 & 2,6 & 0.886 \\
\hline & monoculture & 0.819 & 2,40 & 0.448 \\
\hline & 2-species mix & 0.487 & 2,123 & 0.616 \\
\hline \multirow{3}{*}{ days to first flower } & Individual & 3.5 & 2,6 & 0.098 \\
\hline & monoculture & 2.859 & 2 & 0.239 \\
\hline & 2-species mix & 2.444 & 2 & 0.295 \\
\hline \multirow{3}{*}{ duration of flowering } & Individual & 1.770 & 2 & 0.413 \\
\hline & monoculture & 0.037 & 2,49 & 0.963 \\
\hline & 2-species mix & 0.15 & 2,123 & 0.860 \\
\hline \multirow{3}{*}{ seed weight } & Individual & 10.99 & 2,6 & 0.010 \\
\hline & monoculture & 1.646 & 2,49 & 0.203 \\
\hline & 2-species mix & 2.012 & 2 & 0.366 \\
\hline \multirow{3}{*}{$\begin{array}{l}\text { proportion of seeds } \\
\text { germinated }\end{array}$} & Individual & 2.217 & 2 & 0.345 \\
\hline & monoculture & 2.626 & 2 & 0.269 \\
\hline & 2-species mix & 4.768 & 2 & 0.091 \\
\hline \multirow{3}{*}{ speed of germination } & Individual & 1.083 & 2,6 & 0.397 \\
\hline & monoculture & 7.47 & 2,49 & 0.479 \\
\hline & 2-species mix & 0.795 & 2,123 & 0.545 \\
\hline
\end{tabular}


Table 3. Results of statistical analysis comparing the relative differences between plants in competition and the individual plants at the same dose. Significant endpoints are bolded.

\begin{tabular}{|c|c|c|c|c|c|c|}
\hline Variable & pot type & $F / \chi^{2}$ & df & p-value & \multicolumn{2}{|c|}{ post-hoc } \\
\hline \multirow{4}{*}{ height } & monoculture & 0.865 & 2,40 & 0.429 & \multicolumn{2}{|c|}{1} \\
\hline & & & & & $0<1$ & 0.011 \\
\hline & 2-species mix & 5.173 & 2,123 & 0.007 & $0<5$ & 0.02 \\
\hline & & & & & $1>5$ & 0.98 \\
\hline \multirow{2}{*}{ diameter } & monoculture & 0.819 & 2,40 & 0.448 & \multicolumn{2}{|c|}{1} \\
\hline & 2-species mix & 0.487 & 2,123 & 0.616 & \multicolumn{2}{|c|}{1} \\
\hline \multirow{4}{*}{$\begin{array}{l}\text { days to first } \\
\text { flower }\end{array}$} & monoculture & 2.204 & 2,40 & 0.124 & \multicolumn{2}{|c|}{1} \\
\hline & & & & & $0<1$ & 0.001 \\
\hline & 2-species mix & 37.195 & 2 & $<0.001$ & $0>5$ & 0.001 \\
\hline & & & & & $1>5$ & $<0.001$ \\
\hline \multirow{2}{*}{$\begin{array}{l}\text { duration of } \\
\text { flowering }\end{array}$} & monoculture & 0.78 & 2,40 & 0.465 & \multicolumn{2}{|c|}{1} \\
\hline & 2-species mix & 4.925 & 2 & 0.085 & \multicolumn{2}{|c|}{1} \\
\hline \multirow{4}{*}{ seed weight } & monoculture & 3.662 & 2,40 & 0.035 & \multicolumn{2}{|c|}{1} \\
\hline & & & & & $0>1$ & 0.01 \\
\hline & 2-species mix & 27.068 & 2 & $<0.001$ & $0>5$ & $<0.001$ \\
\hline & & & & & $1>5$ & 0.07 \\
\hline \multirow{2}{*}{$\begin{array}{c}\text { proportion of } \\
\text { seeds germinated }\end{array}$} & monoculture & 1.991 & 2 & 0.369 & \multicolumn{2}{|c|}{1} \\
\hline & 2-species mix & 4.973 & 2 & 0.083 & \multicolumn{2}{|c|}{1} \\
\hline \multirow{2}{*}{$\begin{array}{c}\text { speed of } \\
\text { germination }\end{array}$} & monoculture & 0.503 & 2,40 & 0.609 & \multicolumn{2}{|c|}{1} \\
\hline & 2-species mix & 1.558 & 2,123 & 0.215 & \multicolumn{2}{|c|}{1} \\
\hline
\end{tabular}


Table 4. Calculated percentiles of the marginal posterior distribution of parameters of $S$. noctiflora biomass and $C$. cyanus flower production. Bolded numbers indicate parameter significance.

\begin{tabular}{|c|c|c|c|c|c|c|c|c|c|c|c|}
\hline \multirow{2}{*}{\multicolumn{2}{|c|}{ Parameter percentiles }} & \multicolumn{5}{|c|}{ Silene noctiflora } & \multicolumn{5}{|c|}{ Centaurea cyanus } \\
\hline & & & 2.5 & 50 & 97.5 & $\mathrm{P}(\mathrm{X}>0)$ & & 2.5 & 50 & 97.5 & $\mathrm{P}(\mathrm{X}>0)$ \\
\hline \multicolumn{12}{|c|}{ Parameter and definition } \\
\hline$a$ & $\begin{array}{l}\text { low density effects in } \\
\text { monoculture }\end{array}$ & $\mathrm{a}_{\mathrm{sn}}$ & -50.04 & -24.19 & -7.399 & $\mathbf{0}$ & $\mathrm{a}_{\mathrm{cc}}$ & -77.16 & -53.17 & -15.93 & $\mathbf{0}$ \\
\hline$b$ & $\begin{array}{l}\text { high density effects in } \\
\text { monoculture }\end{array}$ & $b_{\text {sn }}$ & -19.56 & -7.842 & -5.357 & $\mathbf{0}$ & $\mathrm{b}_{\mathrm{cc}}$ & -48.57 & -30.74 & -10.26 & $\mathbf{0}$ \\
\hline$c$ & $\begin{array}{l}\text { competitive effect on other } \\
\text { species }\end{array}$ & $\mathrm{c}_{\mathrm{sn}}$ & -2.554 & -1.622 & -0.969 & $\mathbf{0}$ & $\mathrm{c}_{\mathrm{cc}}$ & 0.1043 & 0.442 & 0.8077 & 0.9955 \\
\hline$\alpha$ & $\begin{array}{l}\text { herbicide influence on } \\
\text { competitive effect in low } \\
\text { density monoculture }\end{array}$ & $\alpha_{\mathrm{sn}}$ & -6.339 & -1.388 & 1.939 & 0.285 & $\alpha_{\mathrm{cc}}$ & -1.019 & 4.396 & 7.158 & 0.8186 \\
\hline$\beta$ & $\begin{array}{l}\text { herbicide influence on } \\
\text { competitive effect in high } \\
\text { density monoculture }\end{array}$ & $\beta_{\mathrm{sn}}$ & -0.043 & 0.0020 & 0.0531 & 0.549 & $\beta_{\mathrm{cc}}$ & -0.0557 & 0.094 & 0.2939 & 0.9025 \\
\hline$\gamma$ & $\begin{array}{l}\text { herbicide influence on } \\
\text { competitive effect on other } \\
\text { species }\end{array}$ & $\gamma_{\mathrm{sn}}$ & -0.923 & -0.093 & 0.207 & 0.299 & $\gamma_{\mathrm{cc}}$ & -0.2654 & -0.1282 & -0.0093 & 0.017 \\
\hline
\end{tabular}


Table 5. Calculated percentiles of the marginal posterior distribution of parameters of $S$. noctiflora biomass and $C$. cyanus seed production. Bolded numbers indicate parameter significance, with probability values of $<0.05$ or $>0.95$ being significant.

\begin{tabular}{|c|c|c|c|c|c|c|c|c|c|c|c|}
\hline \multirow{2}{*}{\multicolumn{2}{|c|}{ Parameter percentiles }} & \multicolumn{5}{|c|}{ Silene noctiflora } & \multicolumn{5}{|c|}{ Centaurea cyanus } \\
\hline & & & 2.5 & 50 & 97.5 & $\mathrm{P}(\mathrm{X}>0)$ & & 2.5 & 50 & 97.5 & $\mathrm{P}(\mathrm{X}>0)$ \\
\hline \multicolumn{12}{|c|}{ Parameter and definition } \\
\hline$a$ & $\begin{array}{l}\text { low density effects in } \\
\text { monoculture }\end{array}$ & $\mathrm{a}_{\mathrm{sn}}$ & -64.80 & -45.79 & -14.40 & $\mathbf{0}$ & $\mathrm{a}_{\mathrm{cc}}$ & -111.7 & -82.31 & -19.74 & $\mathbf{0}$ \\
\hline 6 & $\begin{array}{l}\text { high density effects in } \\
\text { monoculture }\end{array}$ & $\mathrm{b}_{\mathrm{sn}}$ & -63.97 & -48.42 & -15.92 & $\mathbf{0}$ & $\mathrm{b}_{\mathrm{cc}}$ & -31.02 & -17.79 & -7.518 & $\mathbf{0}$ \\
\hline$C$ & $\begin{array}{l}\text { competitive effect on } \\
\text { other species }\end{array}$ & $\mathrm{c}_{\mathrm{sn}}$ & -4.738 & -2.119 & -0.9900 & $\mathbf{0}$ & $\mathrm{c}_{\mathrm{cc}}$ & 0.095 & 0.454 & 0.831 & 0.996 \\
\hline$\alpha$ & $\begin{array}{l}\text { herbicide influence on } \\
\text { competitive effect in } \\
\text { low density } \\
\text { monoculture }\end{array}$ & $\alpha_{\mathrm{sn}}$ & -5.366 & -1.205 & 0.7845 & 0.186 & $\alpha_{\mathrm{cc}}$ & -0.098 & 2.713 & 5.876 & 0.972 \\
\hline$\beta$ & $\begin{array}{l}\text { herbicide influence on } \\
\text { competitive effect in } \\
\text { high density } \\
\text { monoculture }\end{array}$ & $\beta_{\mathrm{sn}}$ & -0.1572 & 0.0183 & 0.2127 & 0.605 & $\boldsymbol{\beta}_{\mathrm{cc}}$ & 0.0068 & 0.0798 & 0.1987 & 0.986 \\
\hline v & $\begin{array}{l}\text { herbicide influence on } \\
\text { competitive effect on } \\
\text { other species }\end{array}$ & $\gamma_{\mathrm{sn}}$ & -7.799 & -5.326 & -1.592 & 0 & $\gamma_{\mathrm{cc}}$ & -0.2734 & -0.1333 & -0.0074 & 0.0194 \\
\hline
\end{tabular}




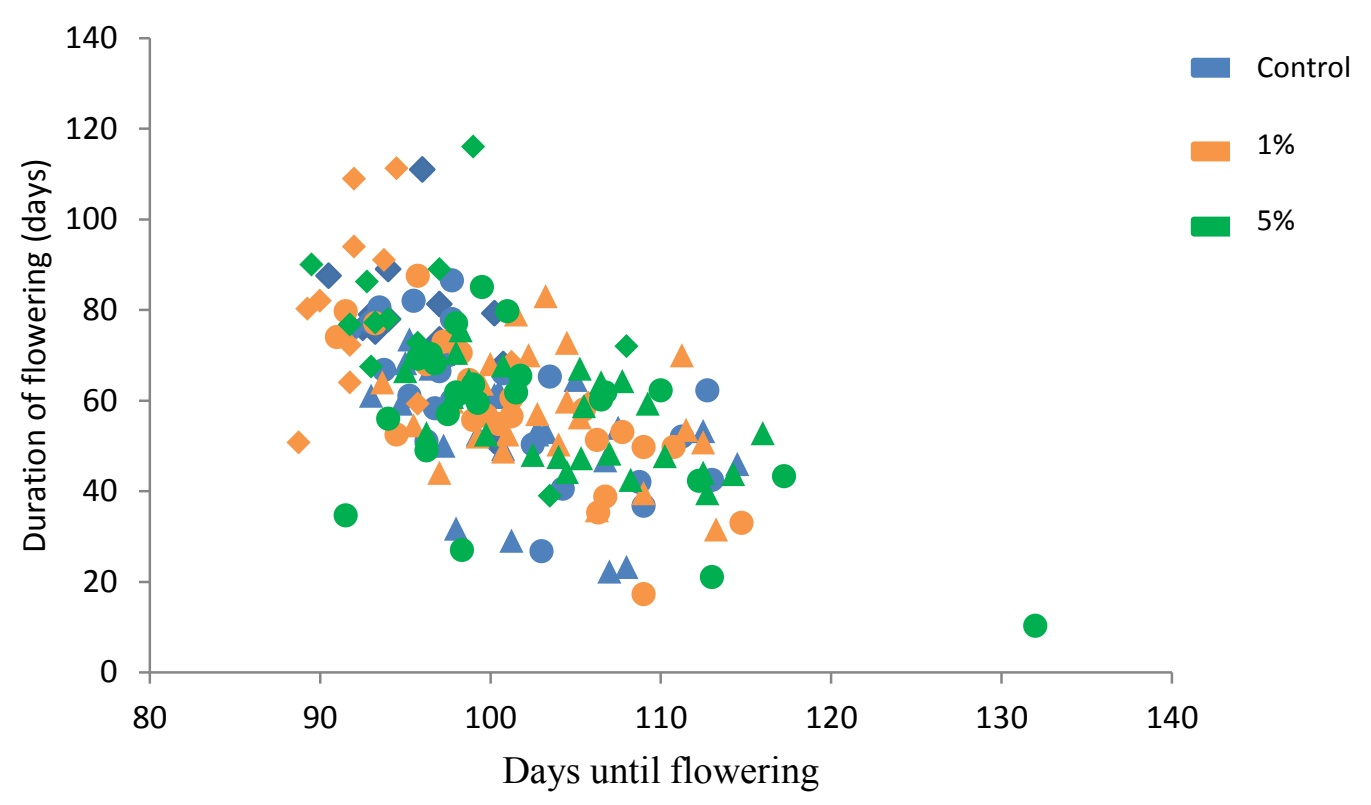

Figure 15. Relationship between the number of days until flowering and the duration of flowering of C. cyanus at different densities and doses of the herbicide glyphosate. Diamond shapes represent low density pots (1-9 plants), circles medium density (16-40 plants), and triangles high density (48-64 plants).

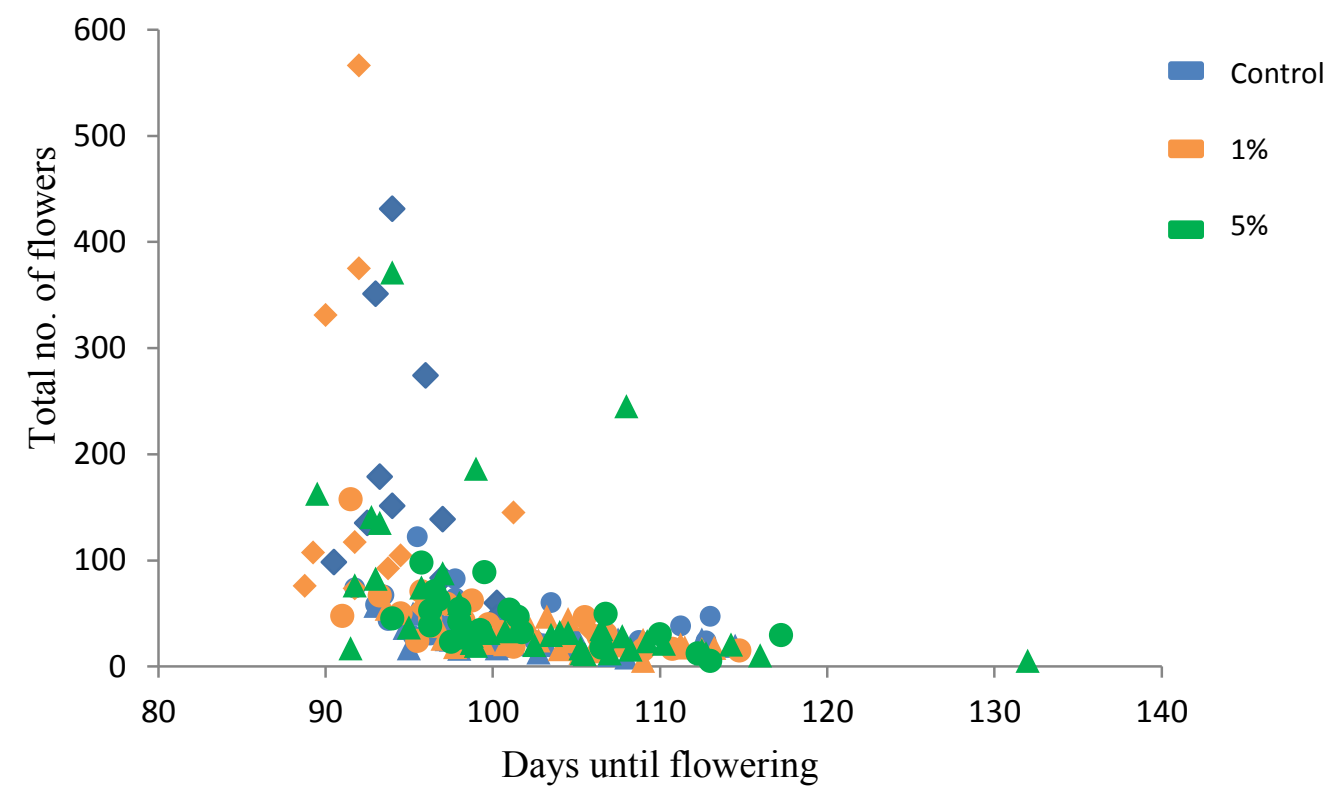

Figure 16. Relationship between the number of days until flowering and the total number of flowers produced by C. cyanus at different densities and doses of the herbicide glyphosate. Diamond shapes represent low density pots (1-9 plants), circles medium density (16-40 plants), and triangles high density (48-64 plants). 


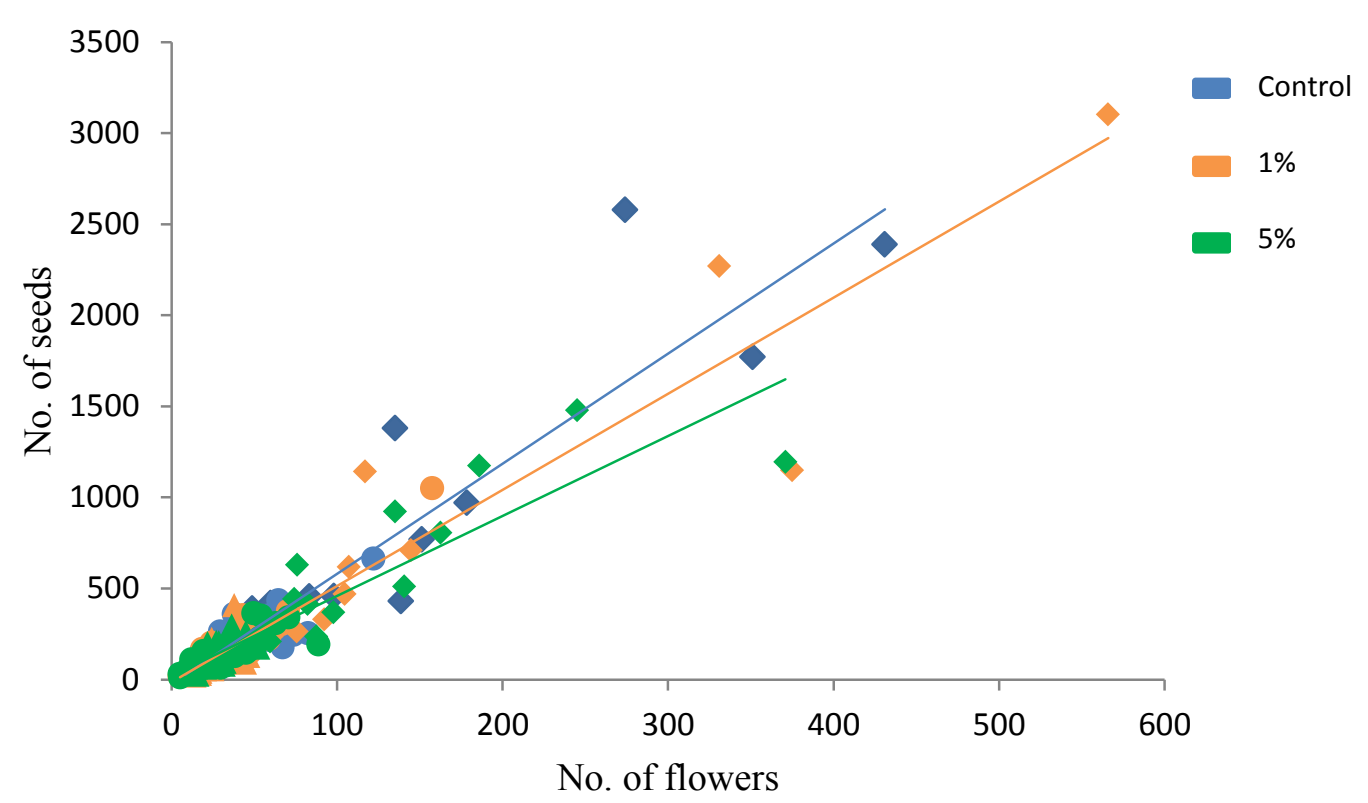

Figure 17. Relationship between C. cyanus flower and seed production at different densities and doses of the herbicide glyphosate. Diamond shapes represent low density pots (1-9 plants), circles medium density (16-40 plants), and triangles high density (48-64 plants).

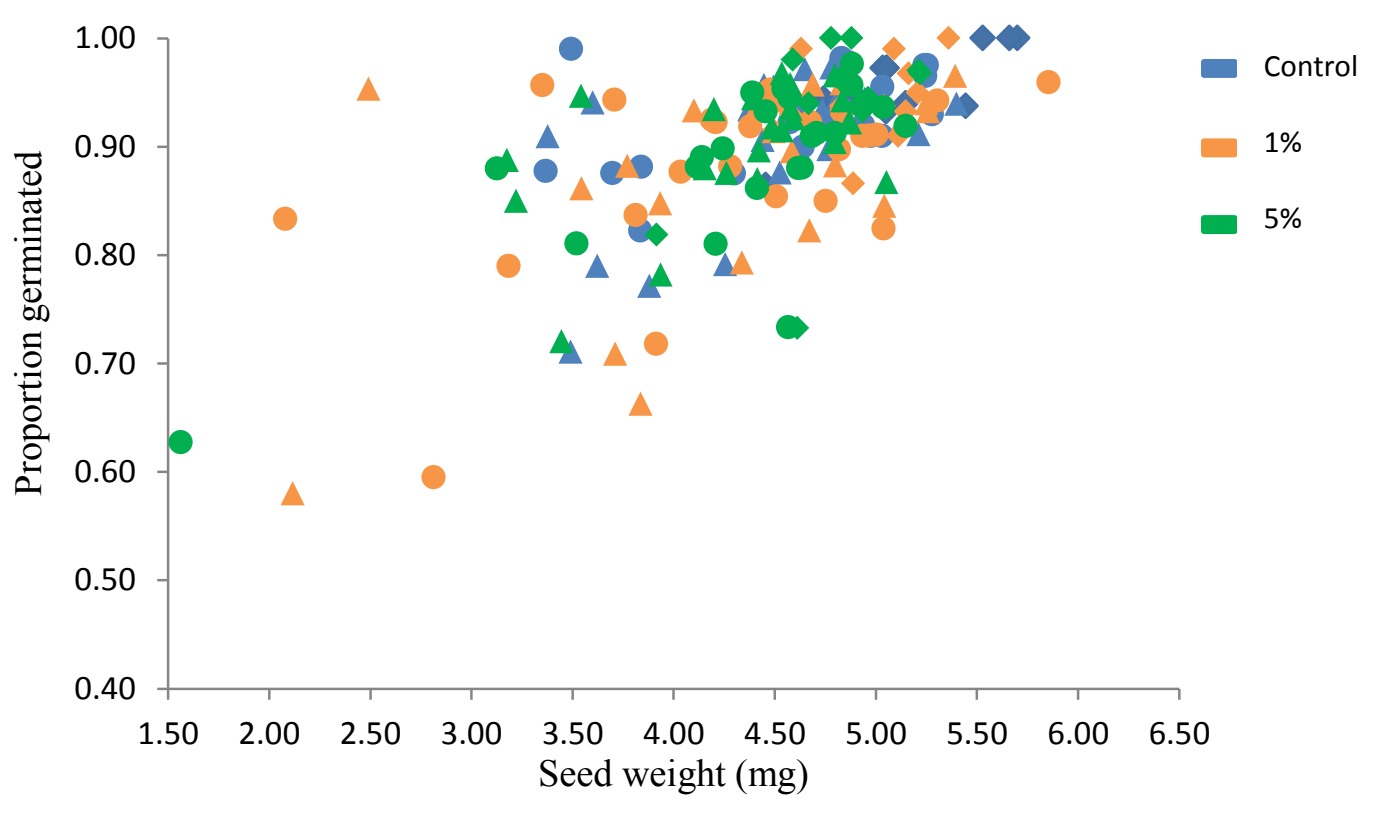

Figure 18. Relationship between C. cyanus seed weight and the proportion of germinated seeds at different densities and doses of the herbicide glyphosate. Diamond shapes represent low density pots (1-9 plants), circles medium density (16-40 plants), and triangles high density (48-64 plants). 


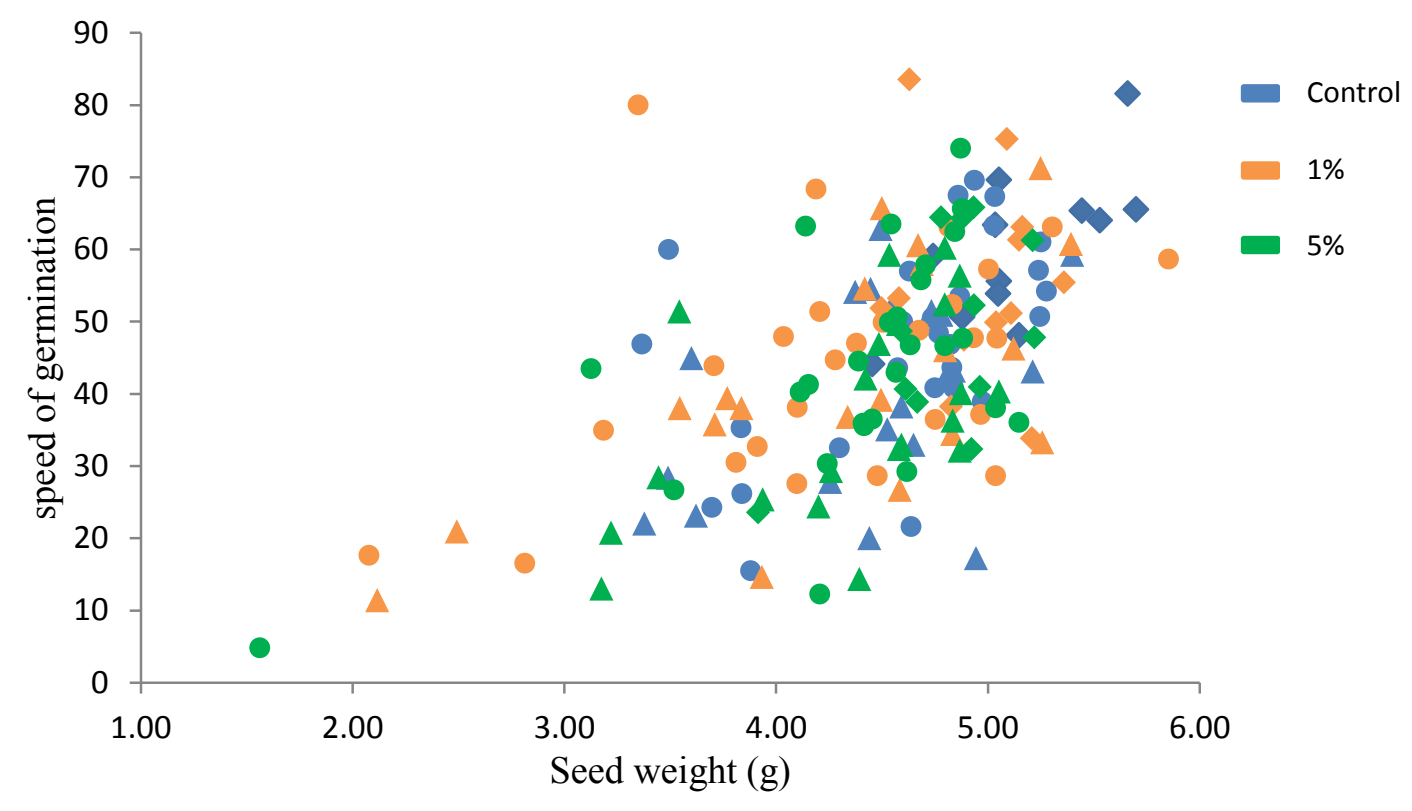

Figure 19. Relationship between $C$. cyanus seed weight and the speed of germination at different densities and doses of the herbicide glyphosate. Diamond shapes represent low density pots (1-9 plants), circles medium density (16-40 plants), and triangles high density (48-64 plants). 


\section{Chapter 4: Discussion}

Environmental Risk assessments for herbicides are performed to ensure that there are no unacceptableeffects on the environment and non-target organisms such as NTTPs, which includes both short and long-term effects. This goal for NTTPs is considered accomplished not only when populations of non-target species are unaffected, but also when communities are not negatively impacted (EFSA 2014). These goals are considered predictable based on the results of individual level or single species tests. The goal of this research was to evaluate the assumption that regulators are protecting NTTP species based on the current ERA guideline procedure of spraying individually potted plants or monocultures. I tested the hypothesis that glyphosate would alter the competitive interactions between $C$. cyanus and S. noctiflora. This study found that the competitive effects of C. cyanus plants on conspecifics increased at both high and low densities when examining its seed production, but not it's flowering, and that the intraspecific competition between $S$. noctiflora plants was not affected by glyphosate. It was also determined that there were effects on the interspecific competitive interactions between $C$. cyanus and $S$. noctiflora were significantly affected by low doses of glyphosate representing drift, confirming the hypothesis. These changes in competitive abilities can translate to changes in population and community dynamics in the longterm.

\section{Density effects}

The density effects as demonstrated in this experiment were not unexpected plant-plant interactions are known to increase with increasing density (Harper 1977), negatively impacting plant performance. The biomass of $S$. noctiflora decreased, and the 
height and diameter of C. cyanus decreased as density increased - this negative relationship between plant size and plant density is probably one of the best studied aspects in plant ecology (Keddy 2001; Damgaard 2004). Increased density also caused delays in flowering, shorter flowering periods, and fewer flowers in C. cyanus. A negative relationship between plant density and seed production was also seen, which can be explained by seed production often being correlated with the size of the plant (Damgaard 2004). There were also slight density effects on seed weight and germination, suggesting that lower quality seeds were produced by plants in high density. Neighbouring plants limit the growth of each other as they compete for limiting resources, and as density increases, the per capita supply of resources decreases (Keddy 2001). This explains the poorer performance in higher densities, and it is rare to find a plant that does not suffer these negative consequences of neighbours (Weiner 1993).

\section{Glyphosate and competition effects on height, time to flower and seed weight}

While there were obvious effects of density on plant performance, dose effects

of glyphosate were more subtle. Although the competition model we used here yields powerful insight into the effects of herbicides on competition, the hyperbolic nature does not fit all of the endpoints. The model can examine differences in monocultures from two-species mixtures, but plants in ERA can be tested individually as well. Therefore differences in responses to herbicide between individual plants and those in mixtures is relevant to test, and this was done by calculating the responses of the plants in mixtures relative to the individual plants of the same dose and comparing these relative values between doses. Height, time to first flower, and seed weight were the endpoints where 
responses of plants in competition varied from individual plants when exposed to glyphosate.

There was a significant relative difference in height between doses when comparing the individual plants to those in two-species mixtures. The C. cyanus plants in mixtures with $S$. noctiflora were all shorter than the individual plants, but were also all similar in height, regardless of dose. This suggests that competition is more important for decreasing height than glyphosate dose. Glyphosate has been documented to decrease height in some species (e.g Flessner et al. 2012; Pfleeger et al. 2012), but hormetic effects have also been seen, where lower doses cause stimulation of growth (Wagner et al. 2003; Cedergreen et al. 2007; Velini et al. 2008). While neither of these situations occurred for the C. cyanus plants in the two-species mixtures, it is important to note for ERA that these plants do not respond the same way as individual plants. Height is an important plant characteristic, related to the plant's ability to capture light. Taller plants intercept more light, and can shade those shorter than them (Falster \& Westoby 2003). Height has also been linked to competitive ability (Schamp et al. 2008), and so effects on height should be predicted accurately in ERA.

There were also significant differences in flowering times between the individual plants and the two-species mixtures of the same dose. The C. cyanus plants in competition exposed to $1 \%$ glyphosate experienced a larger delay in flowering than did the controls. Delays in flowering in wild plants have been seen before with sub-lethal doses of glyphosate (Londo et al. 2014) and other herbicides (e.g. Boutin et al. 2014; Bohnenblust et al. 2016), but these tests were with individual plants. The $5 \%$ dosed plants though, regardless of density, all flowered around the same time. There was also little 
difference between the three doses of the 2-species mixtures, suggesting that competition is a larger driver of delays in flowering than herbicide.

Differences in flowering times between individual plants and those in competition when exposed to glyphosate are important to note as flowering time is important for plant survival, and as seen in this study, it is correlated to other potential measures of reproductive success such as duration of flowering and total number of flowers. Notably, pollinators can be impacted, as they are sensitive to flowering time (Santandreu \& Lloret 1999). Mismatches between flowering time and peak pollinator activity can be detrimental to both the plant (if animal pollination is required for reproduction, such as for C. cyanus) and for the survival of pollinators. If there are fewer flowers available, pollinators may not have enough resources to sustain them when crops are not available for pollination (Carvalheiro et al. 2010), or they may not be able to survive solely on crops alone (Holzschuh et al. 2007).

Seed size can influence factors such as likelihood of germination (e.g. Dolan 1984; Vera 1997; Susko 2006), emergence (e.g. Wulff 1986; Winn 1988; Harrison et al. 2007), survivorship (e.g. Vera 1997; Kidson \& Westoby 2000; Simons \& Johnston 2000), seedling size (e.g. Dolan 1984, Chacon et al. 1998; Susko 2006) and competitive ability (e.g. Dolan 1984; Houssard et al. 1991; Susko \& Cavers 2008). All of these factors can be important in recruitment and sustaining the population size. Generally, large seeds perform better than smaller seeds (reviewed in Ambika et al. 2014), and this was seen in this study as well - heavier seeds were more likely to germinate, and they germinated more quickly than the smaller seeds. These relationships did not vary by dose. However, whether the seedlings of the controls were healthier (for instance examining root length, 
hypocotyl height, wilting, etc.) was not tested. Since seed size can be of such ecological importance, it is essential to understand the effects of herbicides on it under more realistic conditions, such as competition, in ERA.

Glyphosate has been documented to cause decreased seed weights (reviewed in Blackburn \& Boutin 2003), and similar effects have also been seen in other herbicides (e.g. Boutin et al. 2000; Schmitz et al. 2012). In this study, this pattern was observed in the individual plants and to a lesser extent in plants experiencing both intra- and interspecific competition, but it was not significant. There were, though, relative differences between the seed weights of individual plants and those experiencing interspecific competition. This can be explained by the plants in mixture producing seeds of more similar weights, regardless of dose, whereas for the individual plants the seed weights decrease with dose. The dosed seeds were more similar in weight regardless of density, suggesting that competition was the larger driver of reduced seed weight, and glyphosate did not do much more damage than competition had already done.

\section{Changes in competitive interactions}

The competition model demonstrated that the competitive interactions were altered between $C$. cyanus and S. noctiflora when exposed to low doses of glyphosate representing herbicide drift. As interspecific competition influences plant communities (e.g. Rees et al. 1996; Weiher et al. 1998), these changes in interspecific interactions can affect the population dynamics between the two species over time (Damgaard et al. 2008), possibly leading to effects at the community level.

When examining biomass and seed production, both C. cyanus and S. noctiflora were negatively affected by glyphosate, with both of their competitive effects on the 
other being reduced. S. noctiflora's competitive effect was, however, more adversely affected than C. cyanus's, making C. cyanus the stronger competitor at this time. However, this was only the case for seed production, and not at the flower production stage. Therefore glyphosate appears to affect $S$. noctiflora's competitive effect somewhere between C. cyanus's flower and seed production. There is a time lapse between flowering and seed production, and seed production is more resource demanding than flower production (C. cyanus would be taking more resources to produce seeds), but it would be too speculative to suggest reasons for S. noctiflora's change in competitive effect caused by glyphosate during this time period. Changes in competitive effects can arise due to impacts on either species, and so S. noctiflora's competitive effect may have decreased because it was weakened, or because C. cyanus became a stronger competitor when producing seeds. As C. cyanus was also affected only at the seed stage for intraspecific competition, this could suggest the change in interspecific interactions is due to that species, but there is no way to conclusively determine which case occurred in this experiment. , and there

It is known that different species have different sensitivities to herbicides, with sensitivities varying from no effect to complete inhibition, as well as permanent or temporary effects (Damgaard et al. 2014). For instance, monocots are generally more tolerant to herbicides than dicots (e.g. Boutin \& Rogers 2000; McKelvey et al. 2002; White \& Boutin 2007; Riemens et al. 2008). The composition of field margins can be hundreds of species (EFSA 2014), making it likely there is a range of responses. Even slight effects can put more sensitive species at greater disadvantages than the more tolerant ones (EFSA 2014), and these sensitive species can experience increased 
competition from less-affected neighbours (Riemens et al. 2008). This could change the community composition as the susceptible species can be displace by the more tolerant ones (Boutin \& Jobin 1998; Gove et al. 2007; Petersen et al. 2006).

Changes in communities caused by herbicide drift have been seen in previous studies (e.g. Marrs et al. 1991a; Kleijn \& Snoeijing 1997; Gove et al. 2007; Strandberg et al. 2012). Watrud et al. (2011) showed that differences in sensitivity to herbicide causes changes in dominance, by using transgenic oilseed rape which is resistant to glyphosate: a weed species was dominant in the untreated plots, whereas the oilseed rape became dominant in the glyphosate treated plots after two years of drift exposure. Boutin \& Jobin (1998) also found changes in community composition due to intensive farming, but the contributions of just herbicide to the changes could not be determined. Marrs \& Frost (1997) used microcosms to show that the response of a species to herbicide drift depends on the herbicide used and on which species are present with it in mixture - some species showed a response to some herbicides but not others, and responses varied depending on the presence of grasses in the mixture.

This study confirms that herbicides can cause changes in competitive interactions under experimental conditions. Using the same competition model as this study, Damgaard et al. (2008) showed that the interspecific competitive abilities of two weed species were increased at low doses of herbicide mecoprop-P. With a different competition model examining plant coverage of field quadrats, Damgaard et al. (2014) found that the competitive effect of one grass increased while the other decreased with increasing doses of glyphosate. Other studies have also documented differences in sensitivities between terrestrial plants in different densities or grown individually or in 
monocultures and those grown in mixtures (see Table 6: Humphry et al. 2001; Riemens et al. 2008; Riemens et al. 2009; Dalton \& Boutin 2010), suggesting competition plays a role in responses to herbicide. 
Table 6. Studies examining the effects of herbicide on competition or plant mixtures.

\begin{tabular}{|c|c|c|c|c|c|c|c|}
\hline Study & $\begin{array}{c}\text { Purpose related to } \\
\text { density }\end{array}$ & Comparisons & Herbicide & Doses & $\begin{array}{l}\text { Location for } \\
\text { density part } \\
\text { of study }\end{array}$ & Endpoint & $\begin{array}{c}\text { Main result related to } \\
\text { density }\end{array}$ \\
\hline $\begin{array}{l}\text { Dalton \& } \\
\text { Boutin } \\
(2010)\end{array}$ & $\begin{array}{l}\text { Compare responses } \\
\text { of plants grown } \\
\text { singly vs in } \\
\text { microcosms }\end{array}$ & $\begin{array}{l}\text { Monocultures } \\
\text { and multi- } \\
\text { species } \\
\text { microcosms }\end{array}$ & $\begin{array}{l}\text { Glyphosate } \\
\text { and atrazine }\end{array}$ & $\begin{array}{l}\text { Dose- } \\
\text { response }\end{array}$ & $\begin{array}{l}\text { Greenhouse } \\
\text { and field }\end{array}$ & Biomass & $\begin{array}{l}\text { Similar IC25 values between } \\
\text { single species and } \\
\text { microcosms, but changes in } \\
\text { community structure } \\
\text { observed in microcosms }\end{array}$ \\
\hline $\begin{array}{l}\text { Damgaard } \\
\text { et al. (2008) }\end{array}$ & $\begin{array}{l}\text { Examine the } \\
\text { influence of } \\
\text { herbicide on } \\
\text { competitive } \\
\text { interactions }\end{array}$ & $\begin{array}{l}\text { Multiple } \\
\text { densities of } \\
\text { monocultures } \\
\text { and two-species } \\
\text { mixtures } \\
\end{array}$ & Mecoprop-P & $\begin{array}{l}\text { Drift } \\
\text { levels }\end{array}$ & Greenhouse & Biomass & $\begin{array}{l}\text { Interspecific competitive } \\
\text { abilities of both species } \\
\text { increased with increasing } \\
\text { dose }\end{array}$ \\
\hline $\begin{array}{l}\text { Damgaard } \\
\text { et al. }(2014)\end{array}$ & $\begin{array}{l}\text { Test whether the } \\
\text { growth and } \\
\text { competitive effects } \\
\text { of two species are } \\
\text { altered by herbicide }\end{array}$ & $\begin{array}{l}\text { Plots consisting } \\
\text { of two species }\end{array}$ & Glyphosate & $\begin{array}{l}\text { Drift } \\
\text { levels }\end{array}$ & Field & $\begin{array}{l}\text { Cover and } \\
\text { vertical } \\
\text { density }\end{array}$ & $\begin{array}{l}\text { Competitive effect increased } \\
\text { for one species and decreased } \\
\text { for the other }\end{array}$ \\
\hline $\begin{array}{l}\text { Humphrey } \\
\text { et al. (2001) }\end{array}$ & $\begin{array}{l}\text { Examine if plant } \\
\text { density affects the } \\
\text { dose-response } \\
\text { relationship }\end{array}$ & $\begin{array}{l}\text { One species at } \\
\text { densities of two } \\
\text { or } 64\end{array}$ & 2,4-D amine & $\begin{array}{l}\text { Dose- } \\
\text { response }\end{array}$ & $\begin{array}{l}\text { Controlled } \\
\text { environment } \\
\text { room }\end{array}$ & Biomass & $\begin{array}{l}\text { Plants grown at high density } \\
\text { less sensitive to herbicide }\end{array}$ \\
\hline $\begin{array}{l}\text { Riemens et } \\
\text { al. (2008) }\end{array}$ & $\begin{array}{l}\text { Investigate the } \\
\text { effects of herbicide } \\
\text { on vegetation } \\
\text { assemblages }\end{array}$ & $\begin{array}{l}\text { Monocultures } \\
\text { and multi- } \\
\text { species } \\
\text { Mesocosms }\end{array}$ & $\begin{array}{l}\text { Glufosinate } \\
\text { ammonium }\end{array}$ & $\begin{array}{l}\text { Dose- } \\
\text { response }\end{array}$ & Greenhouse & Biomass & $\begin{array}{l}\text { Doses at which effects were } \\
\text { observed differed for species } \\
\text { in mixtures vs species in } \\
\text { monocultures }\end{array}$ \\
\hline $\begin{array}{l}\text { Riemens et } \\
\text { al. (2009) }\end{array}$ & $\begin{array}{l}\text { Determine the effect } \\
\text { of surrounding } \\
\text { vegetation on } \\
\text { individual species } \\
\text { after herbicide spray }\end{array}$ & $\begin{array}{l}\text { Monocultures } \\
\text { and multi- } \\
\text { species } \\
\text { Mesocosms }\end{array}$ & Tepraloxydim & $\begin{array}{l}\text { Dose- } \\
\text { response }\end{array}$ & Greenhouse & Biomass & $\begin{array}{l}\text { Responses between } \\
\text { monocultures and multi- } \\
\text { species mixtures differed - } \\
\text { some species benefited from } \\
\text { being in mixtures, others } \\
\text { were harmed. }\end{array}$ \\
\hline
\end{tabular}




\section{Impacts of plant community changes}

Plants are the foundations of terrestrial community trophic structure (Gleissman 2006). Scientific studies (e.g. Koricheva et al. 2000; Haddad et al. 2009) and metaanalyses (see Balvanera et al. 2006; Cardinale et al. 2006) demonstrate that plant diversity affects the abundance of other organisms such as herbivorous arthropods, parasitoids and predators (Scherber et al. 2012), as these organisms rely on NTTPs for food, habitat and shelter. Herbicide use could therefore lead to higher-level cascades of decline, where the loss of other organisms follows the loss in plant species (Biesmeijer et al. 2006). Bottom-up effects of herbicides on plant communities have been documented. For instance, applications of 2,4-D negatively impacted the population densities of Northern Pocket gophers (Thomomys talpoides) and Least chipmunks (Eutamias minimus) when their primary food source of forbs were eliminated. However, Montane Vole (Microtus montanus) populations increased, as this species benefited from the increased grass cover (Johnson \& Hansen 1969). Changes in arthropod communities have also been noted to be caused indirectly by herbicides, either through loss of host plants or food (e.g. de Snoo 1999; Taylor et al. 2006). This could be harmful to bird species that feed on these insects, for example the Grey Patridge (Perdix perdix) (Potts 1980). Indeed, bird numbers have been linked to arthropod numbers in farm systems (Benton et al. 2002). Therefore, changes in plant communities can affect our ability to protect other organisms.

As biodiversity is related to ecosystem services (Hooper et al. 2005), losses in biodiversity can affect our ability to obtain services from our agroecosystems. These services in agroecosystems go outside the direct benefits such as production of food and 
fibre, but include indirect benefits such as erosion control, nutrient cycling, pollination and sheltering natural enemies of pests. Perhaps the most studied concern today is the loss of pollinators in agroecosystems. Approximately $35 \%$ of global food production is affected by pollinators (Klein et al. 2007), either through required animal pollination or yield and quality is improved with animal pollination (Garratt et al. 2014). Modern agricultural practices decline the suitability of agroecosystems for pollinators (loss of habitat, fewer resources), and therefore there are fewer pollinators present to pollinate crops (Carvell et al. 2006). Plant community composition is important for pollinators for instance, flower diversity has been documented to be positively correlated to bee diversity (Hole et al. 2005), and been linked to moth presence in farmlands (Boutin et al. 2011 and references therein). Studies have shown that herbicides have reduced resources available to pollinators through changing field margin compositions (Lagerlöf et al. 1992; Holzschuh et al. 2007). Herbicides altering the composition of field margins could decrease the contributions of pollinators to crop pollination (Blaauw \& Isaacs 2014). Therefore the ecosystem services that are provided to us by NTTPs should be considered in risk assessment, and this was the new framework presented by EFSA (2014).

\section{Applications to Risk Assessment}

Single species tests for protecting the environment are used because they are inexpensive, quick and simple, while demonstrating clear dose-response patterns that are relatively straightforward. They are also easily standardized and more practical. However there is limited evidence that results from single-species tests can be used to make extrapolations to ecosystem response (Cairns 1984). While further experiments would be beneficial, this study along with a few others (Table 6) suggest that the ERA guideline of 
testing individually potted plants or monocultures is not appropriate for making predictions on the effect of herbicides on wild plant populations and communities as these tests cannot predict possible changes in community structure that may arise as a consequence of changes in competitive interactions. If species have alterations in their competitive interactions, this can have long term consequences for their populations if they are weakened or weakened more than their neighbours, which can lead to the changes in community structure. Therefore including competitive interactions in ERA would improve protections of plant populations by predicting ecologically relevant outcomes of exposure.

Although individual plants or single species tests may not provide ecologically meaningful results, there are several limitations for requesting higher tier tests to be performed. Competition experiments using reproductive endpoints are time and resource consuming, especially if they were to be conducted using perennial species. This would elevate the costs of performing the tests. Using higher tiered testing would be beneficial as to increase realism, but the ability to replicate and standardize would decrease (Dalton \& Boutin 2010). There currently exists no standardized protocol for higher tiered testing involving field studies and multispecies tests (EFSA 2014; Arts et al. 2015). Regulatory agencies should therefore work to establish guidelines for higher tier testing to improve risk assessment. While EFSA is currently working towards developing higher tiered testing, amending extrapolation factors to account for competition would also be useful. However, there currently exist very few studies on herbicide effects on competition (see Table 6), and therefore there is not enough information to be able to calculate such a factor at this time (EFSA 2014). 


\section{Modelling in Risk Assessment}

There is actually very little ecology involved in the ERA assessment process. With the risks being assessed based on the results of individual and single species tests of a few species, usually crops used as proxy for wild species, we are missing many ecological complexities that can affect the risk of the pesticide to populations (Forbes 2009), such as competitive interactions. Therefore, ecological modeling can be a very valuable tool in ERA. Using models such as this one that allow us to see changes in competitive interactions can help in understanding the importance of herbicide applications and their potential influence on populations and communities (Damgaard et al. 2014). This gives us outputs that are closer to the goals of risk assessment (i.e. protecting populations, communities, and ecosystems) (Forbes 2009).

\section{Study limitations}

Risk assessment tests are conducted under ideal greenhouse conditions because this allows the tests to be standardized. However there are obvious differences between greenhouse studies and natural conditions. Climate factors such as temperature and humidity can vary between greenhouses and the field, and these can affect test outcomes by varying growing conditions (EFSA 2014). Natural stressors such as wind, drought and predators are also different, either being absent or controlled in greenhouses (EFSA 2014), and diseases present outdoors could more easily kill plants that have been exposed and weakened by herbicides (Wang \& Freemark 1995). Overall, greenhouse conditions are considered less variable than the natural conditions of the outdoors (Boutin et al. 2010). 
Contradictory results have been obtained when comparing greenhouse and field studies, and often there is poor correspondence between the two (Clark et al. 2004). In a literature review, Fletcher et al. (1990) showed that plants in the field are more sensitive to herbicides. However, plants in the greenhouse studies have often been found to be more sensitive (Riemens et al. 2008; Dalton \& Boutin 2010). Discrepancies are most often explained by environmental variability, as well as variation in the physiological state and plant anatomy (such as growth and cuticle thickness) that arise due to the different conditions in the field versus a greenhouse (Clark et al. 2004). Specific to this study, there is also the added limitation that the physical environment can affect competitive abilities of species (e.g. Eagles \& Williams 1969; Clauss \& Aarseen 1994; see Aarssen 1992). Of course, it is impractical to study all of the interacting factors that occur outdoors (Boutin 2013), but the extent to which all of these conditions affect plant sensitivity to herbicide needs to be examined further (EFSA 2014).

Another limitation is that the $S$. noctiflora did not bolt during the experiment. If they had, this could have changed the dynamic between the two species because of the demand on resources for seed production. However, as C. cyanus does naturally flower and likely produce seeds before S. noctiflora, the resulting dynamics may not have changed if $C$. cyanus finished producing seeds before $S$. noctiflora began. The $S$. noctiflora plants did remain healthy throughout, and were therefore still using resources. Species have different growth rates, and if some species begin flowering and producing seeds earlier than others in the field, a similar situation and result may actually occur.

Although 1 and 5\% doses of glyphosate are realistic, they are on the lower end of the possible amount of drift that occurs. Herbicide drift has been documented to be as 
high as $20-25 \%$ for plants in field margins (de Snoo \& de Wit 1998; Boutin et al. 2011). There is also the possibility that repeated exposures to herbicide drift during the season (Pfleeger et al. 2012) or across years (which can only be studied with perennials) would result in more damage to plants (Schmitz et al. 2012), and this was not considered in the present study. Several studies have also documented combined effects of herbicide and fertilizer applications (Kleijn \& Snoeijing 1997; Damgaard et al. 2011; Strandberg et al. 2012; Schmitz et al. 2014).

\section{Future directions}

As mentioned, more data is required on the effects of herbicide drift on nontarget plants in order to develop more realistic guidelines for ERA or to calculate an uncertainty factor to be used. As such, more studies are required. Currently, the same experiment is being performed in Denmark - same species, but using a different herbicide, Metsulfuron methyl, an herbicide with a different mode of action than glyphosate. Herbicides with different modes of action will affect species differently (sensitivities vary by herbicide), and it is therefore possible the interactions between these two species may be different with another herbicide. This could provide more insight on herbicides affecting competitive interactions. It would also be useful to study this in other species (perennials, different growth patterns and traits) as well in order to demonstrate the effect is applicable to other species and not limited to a subset of non-target plants.

While this study documented changes in competitive interactions, it did not go far enough to study the outcome of these changes. Further research, perhaps longer-term field studies to look at changes in populations over time, would strengthen this area of research by demonstrating the consequences of the changes in interactions. Even further 
modelling to predict the possibility of each of the four ecological scenarios (stable coexistence, species 1 outcompeting species 2 or vice versa, or the outcome depends on the initial abundances of the two species) as a result in the changes in competition (Damgaard 2003; Damgaard 2008) would be beneficial.

\section{Conclusions}

The objective of risk assessment in the context of herbicide registration is to ensure that the chemical is not causing any unacceptable effects on non-target plants (EFSA 2014). As concerns arise over the use of off-target fate of herbicides and other agrochemicals, policy makers must act to protect plant species (Marrs \& Frost 1997). Several studies have demonstrated that many of the current risk assessment test guidelines are not adequate (e.g Boutin et al. 2004; Strandberg et al. 2012; Boutin et al. 2014), and concluded that the guidelines should be amended. This study demonstrates that the ecological simplicity of the current test guidelines may be lacking in their ability to be sufficiently protecting wild plants. If herbicides can alter competitive interactions between species, single species tests may not be suitable to predict the consequences of herbicide exposure at the population and community levels. Field margins are crucial to maintaining biodiversity in agroecosystems, and as plants within them form the base of our ecosystems, effects on NTTPs can have cascading effects on other organisms and on our ecosystem services, and therefore we want to ensure that we are being as protective of wild plants as possible. To do so, competitive interactions may need to be included in risk assessment to make more credible predictions on the effects of herbicide drift on non-target plants. 


\section{References}

Aarssen, L. W. (1992). Causes and consequences of variation in competitive ability in plant communities. Journal of Vegetation Science, 3, 165-174.

Abrams, P. A. (1996). Evolution and the consequences of species introductions and deletions. Ecology, 77, 1321-1328.

Albrecht, H. (2005). Development of arable weed seedbanks during the 6 years after the change from conventional to organic farming. Weed Research, 45, 339-350.

Allaie, R. R., Reshi, Z., Rashid, I., \& Wafai, B. A. (2006). Effect of aqueous leaf leachate of Anthemis cotula - an alien invasive species on germination behaviour of some field crops. Journal of Agronomy and Crop Science, 192, 186-191.

Altieri, M. A. (1999). The ecological role of biodiversity in agroecosystems. Agriculture, Ecosystems \& Environment, 74, 19-31.

Ambika, S., Manonmani, V., \& Somasundaram, G. (2014). Review on effect of seed size on seedling vigour and seed yield. Research Journal of Seed Science, 7, 31-38.

Arts, G. H. P., Dollinger, M., Kohlschmid, E., Maltby, L., Ochoa-Acuña, H., \& Poulsen, V. (2015). An ecosystem services approach to pesticide risk assessment and risk management of non-target terrestrial plants: recommendations from a SETAC Europe workshop. Environmental Science and Pollution Research International, 22, 2350-2355.

Aude, E., Tybirk, K., \& Bruus Pedersen, M. (2003). Vegetation diversity of conventional and organic hedgerows in Denmark. Agriculture, Ecosystems \& Environment, 99, $135-147$.

Ball, D. A. (1992). Weed seedbank response to tillage, herbicides, and crop rotation sequence. Weed Science, 40, 654-659.

Balvanera, P., Pfisterer, A. B., Buchmann, N., He, J. S., Nakashizuka, T., Raffaelli, D., \& Schmid, B. (2006). Quantifying the evidence for biodiversity effects on ecosystem functioning and services. Ecology Letters, 9, 1146-1156.

Baylis, A. D. (2000). Why glyphosate is a global herbicide: Strengths, weaknesses and prospects. Pest Management Science, 56, 299-308.

Benbrook, C. M. (2016). Trends in glyphosate herbicide use in the United States and globally. Environmental Sciences Europe, 28, 1-15. 
Benton, T. G., Bryant, D. M., Cole, L., \& Crick, H. Q. P. (2002). Linking agricultural practice to insect and bird populations: A historical study over three decades. Journal of Applied Ecology, 39, 673-687.

Benjamini, Y., \& Hochberg, Y. (1995). Controlling the false discovery rate : A practical and powerful approach to multiple testing. Journal of the Royal Statistical Societty. Series B (methodological), 57, 289-300.

Bhatti, M., Al-Khatib, K., Felsot, A. S., Parker, R., \& Kadir, S. (1995). Effects of simulated chlorsulfuron drift on fruit yield and quality of sweet cherries (Prunus avium L.). Environmental Toxicology and Chemistry, 14, 537-544.

Biesmeijer, J. C., Roberts, S. P. M., Reemer, M., Ohlemuller, R., Edwards, M., Peeters, T., ... Kunin, W. E. (2006). Parallel declines in pollinators and insect-pollinated plants in Britain and the Netherlands. Science, 313, 351-354.

Blaauw, B. R., \& Isaacs, R. (2014). Flower plantings increase wild bee abundance and the pollination services provided to a pollination-dependent crop. Journal of Applied Ecology, 51, 890-898.

Blackburn, L. G., \& Boutin, C. (2003). Subtle effects of herbicide use in the context of genetically modified crops: A case study with glyphosate (Roundup). Ecotoxicology, $12,271-285$.

Bohnenblust, E. W., Vaudo, A. D., Egan, J. F., Mortensen, D. a., \& Tooker, J. F. (2016). Effects of the herbicide dicamba on nontarget plants and pollinator visitation. Environmental Toxicology and Chemistry, 35, 144-151.

Boutin, C. (2013). Herbicides: Understanding the effects on non-target species. In Encyclopedia of environmental management, Volume II. Taylor \& Francis, New York.

Boutin, C., Baril, A., McCabe, S. K., Martin, P. A., \& Guy, M. (2011). The value of woody hedgerows for moth diversity on organic and conventional farms. Environmental Entomology, 40, 560-569.

Boutin, C., Elmegaard, N., \& Kjaer, C. (2004). Toxicity testing of fifteen non-crop plant species with six herbicides in a greenhouse experiment: Implications for risk assessment. Ecotoxicology, 13, 349-369.

Boutin, C., Freemark, K. E., \& Keddy, C. J. (1995). Overview and rationale for developing regulatory guidelines for nontarget plant testing with chemical pesticides. Environmental Toxicology and Chemistry, 14, 1465-1475.

Boutin, C., \& Jobin, B. (1998). Intensity of agricultural practices and effects on adjacent habitats. Ecological Applications, 8, 544-557. 
Boutin, C., Lee, H., Peart, E. T., Batchelor, P. S., \& Maguire, R. J. (2000). Effects of the sulfonylurea herbicide metsulfuron methyl on growth and reproductuion of five wetland and terrestrial plant species. Environmental Toxicology and Chemistry, 19, 2532-2541.

Boutin, C., \& Rogers, C. A. (2000). Pattern of sensitivity of plant species to various herbicides - an analysis with two databases. Ecotoxicology, 9, 255-271.

Boutin, C., Strandberg, B., Carpenter, D., Mathiassen, S. K., \& Thomas, P. J. (2014). Herbicide impact on non-target plant reproduction: What are the toxicological and ecological implications? Environmental Pollution, 185, 295-306.

Boutin, C., White, A. L., \& Carpenter, D. (2010). Measuring variability in phytotoxicity testing using crop and wild plant species. Environmental Toxicology and Chemistry, 29, 327-337.

Burel, F. (1989). Landscape structure effects on carabid beetles spatial patterns in western France. Landscape Ecology, 2, 215-226.

Cairns, J. (1984). Are single species toxicity tests alone adequate for estimating environmental hazard? Environmental Monitoring and Assessment, 4, 259-273.

Cardinale, B. J., Srivastava, D. S., Duffy, J. E., Wright, J. P., Downing, A. L., Sankaran, M., \& Jouseau, C. (2006). Effects of biodiversity on the functioning of trophic groups and ecosystems. Nature, 443, 989-992.

Carpenter, D., \& Boutin, C. (2010). Sublethal effects of the herbicide glufosinate ammonium on crops and wild plants: Short-term effects compared to vegetative recovery and plant reproduction. Ecotoxicology, 19, 1322-1336.

Carpenter, D., Boutin, C., \& Allison, J. E. (2013). Effects of chlorimuron ethyl on terrestrial and wetland plants: Levels of, and time to recovery following sublethal exposure. Environmental Pollution, 172, 275-282.

Carvalheiro, L. G., Seymour, C. L., Veldtman, R., \& Nicolson, S. W. (2010). Pollination services decline with distance from natural habitat even in biodiversity-rich areas. Journal of Applied Ecology, 47, 810-820.

Carvell, C., Roy, D. B., Smart, S. M., Pywell, R. F., Preston, C. D., \& Goulson, D. (2006). Declines in forage availability for bumblebees at a national scale. Biological Conservation, 132, 481-489.

Cedergreen, N., Streibig, J. C., Kudsk, P., Mathiassen, S. K., \& Duke, S. O. (2007). The occurrence of hormesis in plants and algae. Dose-Response, 5, 150-162. 
Chacon, P., Bustamante, R., \& Henriquez, C. (1998). The effect of seed size on germination and seedling growth of Cryptocarya alba (Lauraceae) in Chile. Revista Chilena De Historia Natural, 71, 189-197.

Clark, J., Ortego, L. S., \& Fairbrother, A. (2004). Sources of variability in plant toxicity testing. Chemosphere, 57, 1599-1612.

Clauss, M. J., \& Aarssen, L. W. (1994). Phenotypic plasticity of size-fecundity relationships in Arabidopsis. Journal of Ecology, 82, 447-455.

Corbet, S. A. (2000). Conserving compartments in pollination webs. Conservation Biology, 14, 1229-1231.

Corbit, M., Marks, P. L., \& Gardescu, S. (1999). Hedgerows as habitat corridors for forest herbs in central New York, USA. Journal of Ecology, 87, 220-232.

Cousens, R. (1991). Aspects of the design and interpretation of competition (interference) experiments. Weed Technology, 5, 664-673.

Craig, I., Woods, N., \& Dorr, G. (1998). A simple guide to predicting aircraft spray drift. Crop Protection, 17, 475-482.

Crone, E. E., Marler, M., \& Pearson, D. E. (2009). Non-target effects of broadleaf herbicide on a native perennial forb: A demographic framework for assessing and minimizing impacts. Journal of Applied Ecology, 46, 673-682.

Dalton, R. L., \& Boutin, C. (2010). Comparison of the effects of glyphosate and atrazine herbicides on nontarget plants grown singly and in microcosms. Environmental Toxicology and Chemistry, 29, 2304-2315.

Damgaard, C. (1998). Plant competition experiments: Testing hypotheses and estimating the probability of coexistence. Ecology, 79, 1760-1767.

Damgaard, C. (2004). Evolutionary ecology of plant-plant interactions: An empirical modelling approach. Aarhus, Denmark: Aarhus University Press.

Damgaard, C., Mathiassen, S. K., \& Kudsk, P. (2008). Modeling effects of herbicide drift on the competitive interactions between weeds. Environmental Toxicology and Chemistry, 27, 1302-1308.

Damgaard, C., Strandberg, B., Mathiassen, S. K., \& Kudsh, P. (2014). The effect of glyphosate on the growth and competitive effect of perennial grass species in seminatural grasslands. Journal of Environmental Science and Health, 49, 897-908.

Damgaard, C., Strandberg, B., Mathiassen, S. K., \& Kudsk, P. (2011). The combined effect of nitrogen and glyphosate on the competitive growth, survival and 
establishment of Festuca ovina and Agrostis capillaris. Agriculture, Ecosystems \& Environment, 142, 374-381.

Davis, B. N. K., \& Williams, C. T. (1990). Buffer zone widths for honeybees from ground and aerial spraying of insecticides. Environmental Pollution, 63, 247-259.

De Snoo, G. R. (1999). Unsprayed field margins: Effects on environment, biodiversity and agricultural practice. Landscape and Urban Planning, 46, 151-160.

De Snoo, G. R., \& de Wit, P. J. (1998). Buffer zones for reducing pesticide drift to ditches and risks to aquatic organisms. Ecotoxicology and Environmental Safety, 41, $112-118$.

Dolan, R. W. (1984). The effect of seed size and maternal source on individual size in a population of Ludwigia leptocarpa (Onagraceae). American Journal of Botany, 71, 1302-1307.

Duke, S. O., Rimando, A. M., Pace, P. F., Reddy, K. N., \& Smeda, R. J. (2003). Isoflavone, glyphosate, and aminomethylphosphonic acid levels in seeds of glyphosate-treated, glyphosate-resistant soybean. Journal of Agricultural and Food Chemistry, 51, 340-344.

Eagles, C. F., \& Williams, D. H. (1969). Effect of photoperiod on vegetative growth in two natural populations of Dactylis glomerata L. Annals of Botany, 35, 271-272.

European Food and Safety Authority. (2014). Scientific Opinion addressing the state of the science on risk assessment of plant protection products for non-target terrestrial plants (Vol. 12).

Egan, J. F., Bohnenblust, E., Goslee, S., Mortensen, D., \& Tooker, J. (2014). Herbicide drift can affect plant and arthropod communities. Agriculture, Ecosystems \& Environment, 185, 77-87.

Elliott, J. G., \& Wilson, B. J. (1983). The influence of weather on the efficiency and safety of pesticide application: The drift of herbicides (BCPC Occasional Publication No. 3). London, UK.

Falster, D. S., \& Westoby, M. (2003). Plant height and evolutionary games. Trends in Ecology and Evolution, 18, 337-343.

Fawcett, R. S., \& Slife, F. W. (1978). Effects of 2,4-D and dalapon on weed seed production and dormancy. Weed Science, 26, 543-547.

Flessner, M. L., McElroy, J. S., Cardoso, L. A., \& Martins, D. (2012). Simulated spray drift of aminocyclopyrachlor on cantaloupe, eggplant, and cotton. Weed Technology, $26,724-730$. 
Fletcher, J. S., Pfleeger, T. G., \& Ratsch, H. C. (1993). Potential environmental risks associated with the new sulfonylurea herbicides. Environmental Science \& Technology, 27, 2250-2252.

Fletcher, J. S., Pfleeger, T. G., Ratsch, H. C., \& Hayes, R. (1996). Potential impact of low levels of chlorsulfuron and other herbicides on growth and yield of nontarget plants. Environmental Toxicology and Chemistry, 15, 1189-1196.

Fletcher, S., Johnson, L., \& McFarlane, J. C. (1990). Influence of greenhouse versus field testing and taxonomic differences on plant sensitivity to chemical treatment. Environmental Toxicology and Chemistry, 9, 769-776.

Forbes, V. E. (2009). The role of ecological modeling in risk assessments seen from an academic's point of view. In P. Thorbek, V. E. Forbes, F. Heimbach, U. Hommen, H. H. Thulke, P. van den Brink, J. Wolgram, V. Grimm (Eds.), Ecological Models for Regulatory Risk Assessments of Pesticides: developing a strategy for the future (pp. 89-96). Pensacola, Florida, USA: CRC Press.

Franz, J. E., Mao, M. K., \& Sikorski, J. A. (1997). Glyphosate: A unique global herbicide. ACS monograph 189. Washington, D.C: American Chemical Society.

Garratt, M. P. D., Breeze, T. D., Jenner, N., Polce, C., Biesmeijer, J. C., \& Potts, S. G. (2014). Avoiding a bad apple: Insect pollination enhances fruit quality and economic value. Agriculture, Ecosystems and Environment, 184, 34-40.

Giesy, J. P., Dobson, S., \& Solomon, K. R. (2000). Ecotoxicological risk assessment for Roundup herbicide. Reviews of Environmental Contamination and Toxicology, 167, $35-120$.

Gleissman, S. R. (2006). The agroecosystem concept. In E. Engles (Ed.), Agroecology: The ecology of sustainable food systems (2nd ed., pp. 23-34). Boca Raton, Florida: Taylor \& Francis group.

Gove, B., Power, S. A., Buckley, G. P., \& Ghazoul, J. (2007). Effects of herbicide spray drift and fertilizer overspread on selected species of woodland ground flora: Comparison between short-term and long-term impact assessments and field surveys. Journal of Applied Ecology, 44, 374-384.

Grimm, V. (2009). Short introduction to ecological modeling. In P. Thorbek, V. E. Forbes, F. Heimbach, U. Hommen, H. H. Thulke, P. van den Brink, J. Wolgram, V. Grimm (Eds.), Ecological Models for Regulatory Risk Assessments of Pesticides: Developing a strategy for the future (pp. 15-26). Pensacola, Florida, USA: CRC Press.

Grover, R., Maybank, J., \& Yoshida, K. (1972). Droplet and vapor drift from butyl ester and dimethylamine salt of 2,4-D. Weed Science, 20, 320-324. 
Haddad, N. M., Crutsinger, G. M., Gross, K., Haarstad, J., Knops, J. M. H., \& Tilman, D. (2009). Plant species loss decreases arthropod diversity and shifts trophic structure. Ecology Letters, 12, 1029-1039.

Harper, J. (1977). Population biology of plants. London, UK: Academic Press.

Harrison, A. S. K., Regnier, E. E., Schmoll, J. T., \& Harrison, J. M. (2007). Seed size and burial effects on giant ragweed (Ambrosia trifida) emergence and seed demise. Weed Science, 55, 16-22.

Hilz, E., \& Vermeer, A. W. P. (2013). Spray drift review: The extent to which a formulation can contribute to spray drift reduction. Crop Protection, 44, 75-83.

Hole, D. G., Perkins, A. J., Wilson, J. D., Alexander, I. H., Grice, P. V., \& Evans, A. D. (2005). Does organic farming benefit biodiversity? Biological Conservation, 122, $113-130$.

Holzschuh, A., Dudenhöffer, J. H., \& Tscharntke, T. (2012). Landscapes with wild bee habitats enhance pollination, fruit set and yield of sweet cherry. Biological Conservation, 153, 101-107.

Holzschuh, A., Steffan-Dewenter, I., Kleijn, D., \& Tscharntke, T. (2007). Diversity of flower-visiting bees in cereal fields: Effects of farming system, landscape composition and regional context. Journal of Applied Ecology, 44, 41-49. R

Hooper, D. U., Chapin, F. S., Ewel, J. J., Hector, A., Inchausti, P., Lavorel, S., ... Wardle, D. A. (2005). Effects of biodiversity on ecosystem functioning: A consensus of current knowledge. Ecological Monographs, 75, 3-35.

Houssard, C., Escarre, J., \& Escarré, J. (1991). The effects of seed weight on growth and competitive ability of Rumex acetosella from two successional old-fields. Oecologia, 86, 236-242.

Humphry, R. W., Mortimer, M., \& Marrs, R. H. (2001). The effect of plant density on the response of Agrostemma githago to herbicide. Journal of Applied Ecology, 38, 1290-1302.

Inouye, B. D. (2001). Response surface experimental designs for investigating interspecific competition. Ecology, 82, 2696-2706.

Isaacs, M. A., Murdock, E. C., Toler, J. E., \& Wallace, S. U. (1989). Effects of lateseason herbicide applications on sicklepod (Cassia obtusifolia) seed production and viability. Weed Science, 37, 761-765. 
Jobin, B., Boutin, C., \& Desgranges, J. (1997). Effects of agricultural practices on the flora of hedgerows and woodland edges in southern Quebec. Canadian Journal of Plant Sciences, 77, 293-299.

Johnson, A. K., Roeth, F. W., Martin, A. R., \& Klein, R. N. (2006). Glyphosate spray drift management with drift-reducing nozzles. Weed Technology, 20, 893-897.

Johnson, D. R., \& Hansen, R. M. (1969). Effects of range treatment with 2,4-D on rodent populations. The Journal of Wildlife Management, 33, 125-132.

Keddy, P. (2001). Competition (2nd ed.). Dordretch, Netherlands: Kluwer Academic.

Kidson, R., \& Westoby, M. (2000). Seed mass and seedling dimensions in relation to seedling establishment. Oecologia, 125, 11-17.

Kleijn, D., \& Snoeijing, G. I. (1997). Field boundary vegetation and the effects of agrochemical drift: botanical change caused by low levels of herbicide and fertilizer. Journal of Applied Ecology, 34, 1413-1425.

Klein, A.-M., Vaissière, B. E., Cane, J. H., Steffan-Dewenter, I., Cunningham, S. A., Kremen, C., \& Tscharntke, T. (2007). Importance of pollinators in changing landscapes for world crops. Proceedings of the Royal Society B: Biological Sciences, 274, 303-313.

Koricheva, J., Mulder, C. P. H., Schmid, B., Joshi, J., \& Huss-Danell, K. (2000). Numerical responses of different trophic groups of invertebrates to manipulations of plant diversity in grasslands. Oecologia, 125, 271-282.

Lagerlöf, J., Stark, J., \& Svensson, B. (1992). Margins of agricultural fields as habitats for pollinating insects. Agriculture, Ecosystems \& Environment, 40, 117-124.

Law, R., \& Watkinson, A. R. (1987). Response-surface analysis of two species competition: An experiment on Phleium arenarium and Vulpia fasciculata. Journal of Ecology, 75, 871-886.

Lichtenberg, E. (2000). Agriculture and the environment. In B. Gardner \& G. Rausser (Eds.), Handbook of Agricultural Economics (Volume 2A, pp. 1249-1313). Amsterdam, The Netherlands: Elsevier.

Liu, L., Punja, Z. K., \& Rhae, J. E. (1997). Altered root exudation and suppression of induced lignification as mechanisms of predisposition by glyphosate of bean roots (Phaseolus vulgaris L.) to colonization by Pythium spp. Physiological and Molecular Plant Pathology, 51, 111-127. 
Londo, J. P., Mckinney, J., Schwartz, M., Bollman, M., Sagers, C., Watrud, L. (2014). Sub-lethal glyphosate exposure alters flowering phenology and causes transient male-sterility in Brassica spp. Plant Biology, 14, 70.

Longley, M., \& Sotherton, N. W. (1997). Factors determining the effects of pesticides upon butterflies inhabiting arable farmland. Agriculture, Ecosystems and Environment, 61, 1-12.

Maccollom, G. B., Currier, W. W., \& Baumann, G. L. (1986). Drift comparisons between aerial and ground orchard application. Journal of Economic Entomology, 79, 459464.

Marrs, R. H., \& Frost, A. J. (1997). A microcosm approach to the detection of the effects of herbicide spray drift in plant communities. Journal of Environmental Management, 50, 369-388.

Marrs, R. H., Frost, A. J., \& Plant, R. A. (1991a). Effect of mecoprop drift on some plant species of conservation interest when grown in standardized mixtures in microcosms. Environmental Pollution, 73, 25-42.

Marrs, R. H., Frost, A. J., \& Plant, R. A. (1991b). Effects of herbicide spray drift on selected species of nature conservation interest: The effects of plant age and surrounding vegetation structure. Environmental Pollution, 69, 223-235.

Marrs, R. H., Frost, A. J., Plant, R. A., \& Lunnis, P. (1993). Effects of herbicides on vegetation. In A. Cooke (Ed.), The environmental effects of Pesticide drift. Peterborough: English Nature.

Marrs, R. H., Williams, C. T., Frost, A. J., \& Plant, R. A. (1989). Assessment of the effects of herbicide spray drift on a range of plant species of conservation interest. Environmental Pollution, 59, 71-86.

Marshall, E. J. P., \& Moonen, A. C. (2002). Field margins in northern Europe: Their functions and interactions with agriculture. Agriculture, Ecosystems \& Environment, $89,5-21$.

Maybank, J., Yoshida, K., \& Grover, R. (1978). Spray drift from agricultural pesticide applications. Journal of the Air Pollution Control Association, 28, 1009-1014.

McKelvey, R. A., Wright, J. P., \& Honegger, J. L. (2002). A comparison of crop and non-crop plants as sensitive indicator species for regulatory testing. Pest Management Science, 58, 1161-1174.

McNeill, J. (1980). The biology of canadian weeds. 46. Silene noctiflora L. Canadian Journal of Plant Science, 60, 1243-1253. 
Millenium Ecosystem Assessment. (2005). Ecosystems and human well-being: Synthesis. Washington, D.C.

Monsanto (2015). Agricultural seeds. Retrieved from $\mathrm{http} / / /$ www.monsanto.com/products/pages/monsanto-agricultural-seeds.aspx

Monsanto. (2014). What is glyphosate? Retrieved from http://www.monsanto.com/sitecollectiondocuments/glyphosate-safety-health.pdf

Murphy, S. D., Miller, P. C. H., \& Parkin, C. S. (2000). The effect of boom section and nozzle configuration on the risk of spray drift. Journal of Agricultural Engineering Research, 75, 127-137.

Nicholls, C. I., \& Altieri, M. A. (2013). Plant biodiversity enhances bees and other insect pollinators in agroecosystems. A review. Agronomy for Sustainable Development, $33,257-274$.

Norris, K. (2008). Agriculture and biodiversity conservation: Opportunity knocks. Conservation Letters, 1, 2-11.

OECD. (2006). OECD Test guideline 227: Terrestrial Plant Test - Vegetative Vigour, Paris, France.

Olson, D. M., \& Wäckers, F. L. (2007). Management of field margins to maximize multiple ecological services. Journal of Applied Ecology, 44, 13-21.

Petersen, S., Axelsen, J. A., Tybirk, K., Aude, E., \& Vestergaard, P. (2006). Effects of organic farming on field boundary vegetation in Denmark. Agriculture, Ecosystems and Environment, 113, 302-306.

Pfleeger, T., Blakeley-Smith, M., King, G., Lee, E. H., Plocher, M., \& Olszyk, D. (2012). The effects of glyphosate and aminopyralid on a multi-species plant field trial. Ecotoxicology, 21, 1771-1787.

Pline, W. A., Wells, R., Little, G., Edminsten, K. L., \& Wilcut, J. W. (2003a). Glyphosate and water-stress effects on fruiting and carbohydrates in glyphosate-resistant cotton. Crop Science, 48, 879-885.

Pline, W., Edmisten, K., Wilcut, J., Wells, R., \& Thomas, J. (2003b). Glyphosate-induced reductions in pollen viability and seed set in glyphosate-resistant cotton and attempted remediation by gibberellic acid $\left(\mathrm{GA}_{3}\right)$. Weed Science, 51, 19-27.

Potts, G. R. (1980). The effects of modern agriculture, nest predation and game management on the population ecology of Partridges (Perdix perdix and Alectoris rufa). Advances in Ecological Research, 11, 2-79. 
Reddy, K. N., Rimando, A. M., \& Duke, S. O. (2004). Aminomethylphosphonic acid, a metabolite of glyphosate, causes injury in glyphosate-treated, glyphosate-resistant soybean. Journal of Agricultural and Food Chemistry, 52, 5139-5143.

Rees, M., Grubb, P. J., \& Kelly, D. (1996). Quantifying the impact of competition and spatial heterogeneity on the structure and dynamics of a four-species guild of winter annuals. The American Naturalist, 147, 1-32.

Riemens, M. M., Dueck, T., \& Kempenaar, C. (2008). Predicting sublethal effects of herbicides on terrestrial non-crop plant species in the field from greenhouse data. Environmental Pollution, 155, 141-149.

Riemens, M. M., Dueck, T., Kempenaar, C., Lotz, L. A. P., \& Kropff, M. J. J. (2009). Sublethal effects of herbicides on the biomass and seed production of terrestrial noncrop plant species, influenced by environment, development stage and assessment date. Environmental Pollution, 157, 2306-2313.

Rokich, D. P., Harma, J., Turner, S. R., Sadler, R. J., \& Tan, B. H. (2009). Fluazifop-pbutyl herbicide: Implications for germination, emergence and growth of Australian plant species. Biological Conservation, 142, 850-869. Retrieved from

Santandreu, M., \& Lloret, F. (1999). Effect of flowering phenology and habitat on pollen limitation in Erica multiflora. Canadian Journal of Botany, 77, 734-743.

Schamp, B. S., Chau, J., \& Aarssen, L. W. (2008). Dispersion of traits related to competitive ability in an old-field plant community. Journal of Ecology, 96, 204212 .

Scherber, C., Eisenhauer, N., Weisser, W. W., Schmid, B., Voigt, W., Fischer, M., ... Tscharntke, T. (2012). Bottom up effects of plant diversity on multitrophic interactions. Nature, 468, 553-556.

Schmitz, J., Schäfer, K., \& Brühl, C. A. (2014). Agrochemicals in field margins-field evaluation of plant reproduction effects. Agriculture, Ecosystems \& Environment, 189, 82-91.

Schmitz, J., Stahlschmidt, P., \& Brühl, C. A. (2012). Protection of terrestrial non-target plant species in the regulation of environmental risks of pesticides. Report Gz. Z6 93104-4/10.Main Report. FKZ 36003053

Simons, A. M., \& Johnston, M. (2000). Variation in seed traits of Lobelia inflata (Campanulaceae): Sources and fitness consequences. American Journal of Botany, $87,124-132$.

Strandberg, B., Mathiassen, S. K., Bruus, M., Kjaer, C., Andersen, H. V., Bossi, R., ... Kudsk, P. (2012). Effects of herbicides on non-target plants: How do effects in 
standard plant tests relate to effects in natural habitats? Pesticide Research No. 137. Copenhagen, Denmark.

Susko, D. J. (2006). Effect of ovule position on patterns of seed maturation and abortion in Robinia pseudoacacia (Fabaceae). Canadian Journal of Botany.

Susko, D. J., \& Cavers, P. B. (2008). Seed size effects and competitive ability in Thlaspi arvense L. (Brassicaccae). Botany, 86, 259-267.

Sutcliffe, O. L., \& Kay, Q. O. N. (2000). Changes in the arable flora of central southern England since the 1960s. Biological Conservation, 93, 1-8.

Svensson, R., \& Wigren, M. (1984). History and biology of Centaurea cyanus in Sweden. Svensk botanisk tidskrift, 79, 273-297.

Taylor, R. L., Maxwell, B. D., \& Boik, R. J. (2006). Indirect effects of herbicides on bird food resources and beneficial arthropods. Agriculture, Ecosystems \& Environment, $116,157-164$.

Taylor, S. E., \& Oliver, L. R. (1997). Sicklepod (Senna obtusifolia) seed production and viability as influenced by late-season postemergence herbicide applications. Weed Science, 45, 497-501.

Tomlin, C. D. S. (2000). The pesticide manual (12th ed., Vol. 28). Farnham, Surrey, UK: British Crop Protection Council.

United States Environmental Protection Agency. (2011). Pesticides industry sales and usage: 2006 and 2007 Market Estimates. Washington, D.C.

United States Environmental Protection Agency. (2012). Ecological effects test guidelines: Vegetative vigor - OCSPP 850.4150, EPA 712-C-011; Early seedling growth toxicity test - OCSPP 850.4230, EPA 712-C-010; Seedling emergence and seedling growth - OCSPP 850.4100, EPA 712-C-012. Washington, D.C.

United States Environmental Protection Agency. (2015). Reducing herbicide drift. Retrieved from http://www2.epa.gov/reducing-pesticide-drift/introduction-pesticidedrift

Velini, E. D., Alves, E., Godoy, M. C., Mescheded, D. K., Souza, R., \& Duke, S. O. (2008). Glyphosate applied at low doses can stimulate plant growth. Pest Management Science, 64, 489-496.

Vera, M. L. (1997). Effects of altitude and seed size on germination and seedling survival of heathland plant in north Spain. Plant Ecology, 133, 101-106. 
Vitousek, P. M., Mooney, H. A, Lubchenco, J., \& Melillo, J. M. (1997). Human domination of Earth's ecosystems. Science, 277, 494-499.

Wagner, R., Kogan, M., \& Parada, A. M. (2003). Phytotoxic activity of root absorbed glyphosate in corn seedlings (Zea mays L.). Weed Biology and Management, 3, $228-$ 232.

Wall, D. A., Derksen, D. A., Friesen, L. F., \& Technology, W. (1995). Canola (Brassica napus) response to simulated sprayer contamination with thifensulfuron and thifensulfuron:Tribenuron (2:1). Weed Technology, 9, 468-476.

Wang, W., \& Freemark, K. (1995). The use of plants for environmental monitoring and assessment. Ecotoxicology and Environmental Safety, 30, 289-301.

Watrud, L. S., King, G., Londo, J. P., Colasanti, R., Smith, B. M., Waschmann, R. S., \& Lee, E. (2011). Changes in constructed Brassica communities treated with glyphosate drift. Ecological Applications, 21, 525-538.

Weidenhamer, J. D., Hartnett, D. C., Romeo, J. T., Weidenhamer, B. Y. J. D., \& Hartnettt, D. C. (1989). Density-dependent phytotoxicity: Distinguishing resource competition and allelopathic interference inplants. Journal of Applied Ecology, 26, 613-624.

Weiher, E., Clarke, G. D. P., \& Keddy, P. A. (1998). Community assembly rules, morphological dispersion, of plant species the coexistence. Oikos, 81, 309-322.

Weiner, J. (1993). Competition among plants. Treballs de La Societat Catalana de Biologia, 44, 99-109.

Weisser, P., Landfried, M., \& Koch, H. (2002). Off-crop drift sediments on plant surfaces - exposure of non-target organisms. Aspects of Applied Biology, 66, 225-230.

White, A., \& Boutin, C. (2007). Herbicidal effects on nontarget vegetation: Investigating the limitations of current pesticide registration guildelines. Environmental Toxicology and Chemistry, 26, 2634-2643.

Winn, A. A. (1988). Ecological and evolutionary consequences of seed size in Prunella vulgaris. Ecology, 69, 1537-1544.

Woodburn, A. T. (2000). Glyphosate: Production, pricing and use worldwide. Pest Management Science, 56, 309-312.

Wulff, R. D. (1986). Seed size variation in Desmodium paniculatum: Effects on reproductive yield and competitive ability. Journal of Ecology, 74, 115-121. 
Young, B. G. (2006). Changes in herbicide use patterns and production practices resulting from glyphosate-resistant crops. Weed Technology, 20, 301-307. 
Appendix 1. Visual Assessments

Table 1. Visual rating system for plants used to assess herbicidal damage each week after exposure to 1 and $5 \%$ of the recommended label rate of glyphosate.

\begin{tabular}{ccl} 
Rank & \% Size Compared to Controls & \multicolumn{1}{c}{ General Characteristics } \\
\hline \hline 0 & $100 \%$ & Healthy; Similar to the controls \\
2 & Slightly smaller than controls & $\begin{array}{l}\text { Minor herbicide effects (chlorosis, discoloration) but no obvious size difference } \\
\text { from controls }\end{array}$ \\
3 & $\sim 75 \%$ & Mild herbicide damage resulting in obvious, but minimal, reduced growth \\
4 & $>50 \%,<75 \%$ & Obvious herbicide damage \\
5 & $\sim 50 \%$ & Plants stunted, often with significant damage \\
6 & $>25 \%,<50 \%$ & Plants stunted, severe damage \\
7 & $>10 \% ;<25 \%$ & Severe damage, unlikely to recover \\
8 & $<10 \%$, or nearly dead & Severe damage, likely to die \\
9 & $0 \%$ & Dead \\
\hline
\end{tabular}



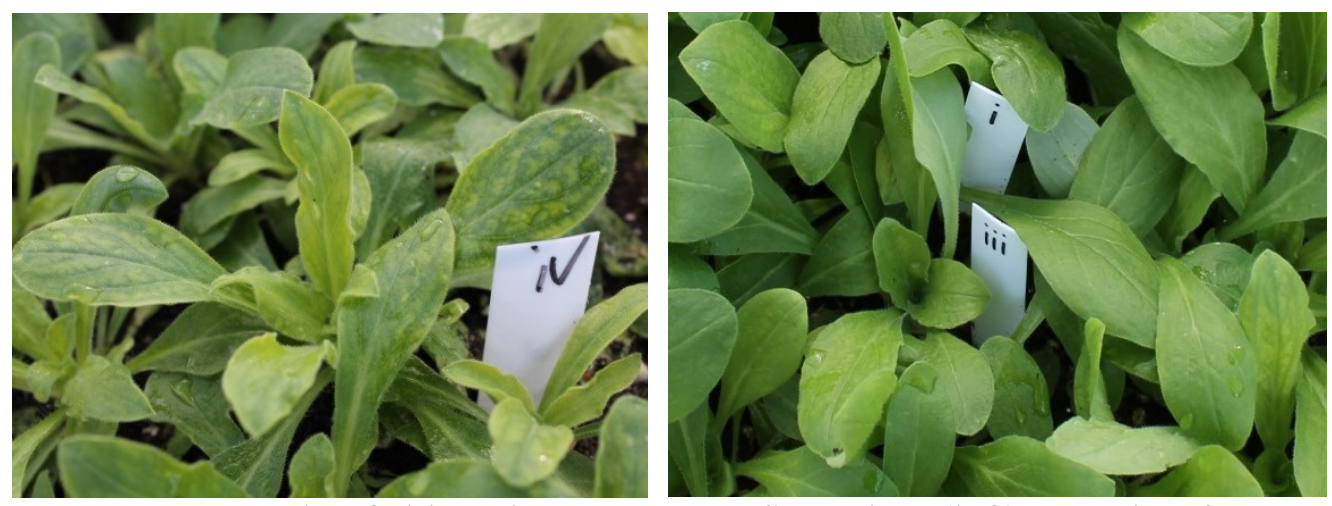

Figure 1. Example of chlorosis on a $S$. noctiflora plant (left) 3 weeks after exposure to $5 \%$ of the recommended application rate of glyphosate. This was ranked 4 by the observer, due to the smaller size of the plant and the obvious chlorosis in comparison to the control (right).

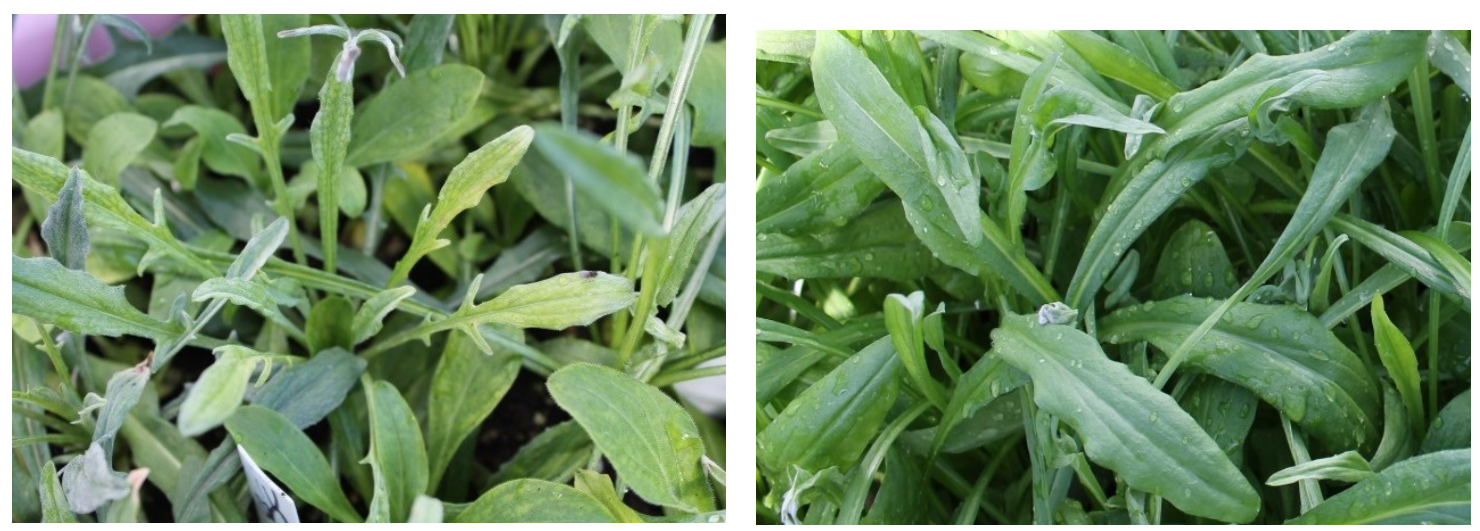

Figure 2. Example of chlorosis on a C. cyanus plant (left) 3 weeks after exposure to $5 \%$ of the recommended application rate of glyphosate. This was ranked 5 by the observer due to the extreme small size of the plant and the significant chlorosis in comparison to the control (right). 